\title{
Endogenous, tissue-resident stem/ progenitor cells in gonads and bone marrow express FSHR and respond to FSH via FSHR-3
}

Deepa Bhartiya ${ }^{1 *} \mathbb{D}$, Hiren Patel ${ }^{1,2}$, Ankita Kaushik ${ }^{1}$, Pushpa Singh ${ }^{1}$ and Diksha Sharma ${ }^{1}$

\begin{abstract}
Follicle stimulating hormone (FSH) is secreted by the anterior pituitary and acts on the germ cells indirectly through Granulosa cells in ovaries and Sertoli cells in the testes. Extragonadal action of FSH has been reported but is still debated. Adult tissues harbor two populations of stem cells including a reserve population of primitive, small-sized, pluripotent very small embryonic-like stem cells (VSELs) and slightly bigger, tissue-specific progenitors which include ovarian stem cells (OSCs) in ovaries, spermatogonial stem cells (SSCs) in testes, endometrial stem cells (EnSCs) in uterus and hematopoietic stem cells (HSCs) in the bone marrow. Data has accumulated in animal models showing FSHR expression on both VSELs and progenitors in ovaries, testes, uterus and bone marrow and eventually gets lost as the cells differentiate further. FSH exerts a direct action on the stem/progenitor cells via alternatively spliced FSHR-3 rather than the canonical FSHR-1. FSH stimulates VSELs to undergo asymmetrical cell divisions to self-renew and give rise to the progenitors that in turn undergo symmetrical cell divisions and clonal expansions followed by differentiation into specific cell types. Excessive self-renewal of VSELs results in cancer and this explains ubiquitous expression of embryonic markers including nuclear OCT-4 along with FSHR in cancerous tissues. Focus of this review is to compile published data to support this concept. FSHR expression in stem/progenitor cells was confirmed by immuno-fluorescence, Western blotting, in situ hybridization and by quantitative RT-PCR. Two different commercially available antibodies (Abcam, Santacruz) were used to confirm specificity of FSHR expression along with omission of primary antibody and pre-incubation of antibody with immunizing peptide as negative controls. Western blotting allowed detection of alternatively spliced FSHR isoforms. Oligoprobes and primers specific for Fshr-1 and Fshr-3 were used to study these alternately-sliced isoforms by in situ hybridization and their differential expression upon FSH treatment by qRT-PCR. To conclude, stem/progenitor cells in adult tissues express FSHR and directly respond to FSH via FSHR-3. These findings change the field of FSH-FSHR biology, call for paradigm shift, explain FSHR expression on cancer cells in multiple organs and provide straightforward explanations for various existing conundrums including extragonadal expression of FSHR.
\end{abstract}

Keywords: FSH, FSHR, FSHR-3, Ovary, Testis, Uterus, Bone marrow, Very small embryonic-like stem cells (VSELs)

\footnotetext{
*Correspondence: bhartiyad@nirrh.res.in

${ }^{1}$ Stem Cell Biology Department, ICMR- National Institute for Research in Reproductive Health, Jehangir Merwanji Street, Parel, Mumbai 400 012, India

Full list of author information is available at the end of the article
}

\section{Key points}

- Two populations of stem cells exist in multiple adult tissues including quiescent VSELs and slightly bigger, tissue-specific progenitors including OSCs in ovaries, SSCs in testes, EnSCs in the uterus, HSCs in the bone marrow and so on in other adult organs as well.

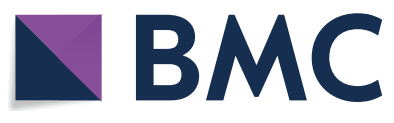

(c) The Author(s) 2021. Open Access This article is licensed under a Creative Commons Attribution 4.0 International License, which permits use, sharing, adaptation, distribution and reproduction in any medium or format, as long as you give appropriate credit to the original author(s) and the source, provide a link to the Creative Commons licence, and indicate if changes were made. The images or other third party material in this article are included in the article's Creative Commons licence, unless indicated otherwise in a credit line to the material. If material is not included in the article's Creative Commons licence and your intended use is not permitted by statutory regulation or exceeds the permitted use, you will need to obtain permission directly from the copyright holder. To view a copy of this licence, visit http://creativecommons.org/licenses/by/4.0/. The Creative Commons Public Domain Dedication waiver (http://creativeco mmons.org/publicdomain/zero/1.0/) applies to the data made available in this article, unless otherwise stated in a credit line to the data. 
These stem/progenitor cells express FSHR which eventually gets degraded as cells differentiate further into tissue-specific mature cell types. Existing dogma that FSH action is limited to Granulosa cells in ovaries and Sertoli cells in the testes needs an urgent revision.

- FSH acts directly on the VSELs that exist in all adult tissues including ovaries, testes, uterus and bone marrow. FSH exerts a direct effect on the stem/progenitor cells and promotes asymmetrical, symmetrical divisions and clonal expansion. FSH effects on extragonadal tissues including uterus and bone marrow stem/progenitor cells is clearly delineated in this review.

- In addition to the existing dogma that FSH exerts an indirect action on the germ cells via Sertoli cells in testes or granulosa cells in the ovaries, FSH directly affects testicular and ovarian stem cells.

- FSH action on the stem/progenitor cells is mediated via Fshr-3 which is alternately spliced, growth factor type-1 receptor that acts via calcium signaling and the ERK/MAPK pathway.

- Stem cells are involved in both endometrial regeneration and hematopoiesis in bone marrow and FSH has a potential role in both these processes.

- Expression of FSHR on VSELs and OSCs in the ovaries explains why commercially available ovarian cancer cell lines when treated with FSH do not show increase in cAMP. Gonadotropin theory with a potential role of stem cells in the OSE could possibly explain initiation of ovarian cancer.

- Our findings explain extragonadal expression of FSHR in the uterus. FSH exerts direct action on both endometrial and myometrial stem cells. Various uteropathies have a stem cell basis and this explains FSHR expression in clinical samples of endometriosis, endometrial cancers as well as myomas.

- Several folds increased Fshr-3 in testicular cancer samples is intriguing and suggests a role of FSH in initiating testicular cancer similar to gonadotropin theory that exists for ovarian cancer.

\section{Main text}

It is textbook information, after almost 90 years of research since follicle-stimulating hormone (FSH) was first reported in 1930s, that FSH is secreted by the anterior pituitary and acts on granulosa cells in the ovarian pre-antral follicles and on Sertoli cells in the testes [1]. It facilitates follicular growth and spermatogenesis and thus plays a central role in mammalian reproduction. FSH is critical for preantral to later-stage follicle development, whereas early-stage follicle development (primordial to primary stages) is thought to be independent of FSH action. FSH exerts an indirect effect on the germ cells in the testes by stimulating Sertoli cells to secrete growth factors required for germ cells proliferation/differentiation. Besides physiologic, FSH also exerts therapeutic effect on the gonads and is used in the ART Clinics to stimulate the ovaries to generate multiple eggs for infertile couples and in men with hypogonadotropic hypogonadism. In recent times, it has also been suggested to treat men with idiopathic infertility with FSH and to evolve 'testicular hyperstimulation' regimens [2, 3]. Published reports regarding FSHR expression on multiple extra-gonadal adult tissues and also on cancer cells affecting multiple organs has raised many eyebrows [4] and we have recently addressed various concerns [5].

Present review is a compilation of the work published since 2013 suggesting that FSHR are expressed on the tissue-resident stem/progenitor cells in multiple organs including bone marrow and reproductive tissues ovaries, testes and uterus. These results call for a paradigm shift in the field since evidently FSH exerts a direct action on the stem cells via Fshr-3 rather than the canonical Fshr-1 isoform. Tissue-resident stem cells that exist in adult tissues are the very small embryonic-like stem cells (VSELs) and were recently reviewed [6-8]. FSHR expression on stem/progenitor cells completely renovates the field of FSH/FSHR biology and provides straightforward explanations for various existing conundrums in the field including extragonadal expression of FSHR [1, 5, 9-11]. FSHR expression is reported on murine embryonic stem $(\mathrm{mES})$ cell line (ES-D3) and teratocarcinoma cell lines P19 and NTera2 [12]. A scRNAseq study has reported low-level expression of FSHR transcripts only in female FGC 4 (oogenesis) and male FGC 3 (mitotic arrest) [13] rather than in the somatic cells in gonadal ridges. VSELs are developmentally linked to primordial germ cells [7] and both mES cells and teratocarcinoma cell lines (more primitive to primordial germ cells) also express FSHR. Thus, FSHR expression on VSELs is along the expected lines and should not surprise the readers.

\section{Ovarian stem cells}

It is widely believed and textbook information that FSH acts on Granulosa cells in the ovaries and Sertoli cells in the testes [1]. However, besides granulosa cells, FSHR expression has also been reported on ovary surface epithelial (OSE) cells by several groups. Also, Fshr-3 was suggested to be the predominant isoform in sheep ovarian follicles. More than $90 \%$ of ovarian cancers initiate in the OSE however, OSE cells remain poorly studied till date. Alternately spliced FSHR isoforms have been reported in clinical samples, ovarian cancers and also on serous ovarian cell lines [14-16]. Contradictory views 
Table 1 Result highlights of the study published by Li et al. [18] showing tumorigenic ID8 ovary cancer surface epithelial cells are affected by FSH via FSHR-3

\begin{tabular}{|c|c|}
\hline Experiments & Results highlights \\
\hline In vitro studies & $\begin{array}{l}\text { ID8, a tumorigenic cell line derived from mouse ovarian surface epithelial cells when exposed to EGF }(10 \mathrm{ng} / \mathrm{ml}) \text { or FSH }(20 \mathrm{ng} / \\
\text { ml), showed greater proliferation response after FSH treatment compared to EGF in vitro. }\end{array}$ \\
\hline Associated signaling & $\begin{array}{l}\text { The canonical FSHR-1 is associated with stimulation of adenylate cyclase whereas the growth factor variant FSHR-3 signals } \\
\text { via ERK1/2 activation and calcium influx in the absence of increased intracellular concentrations of cAMP. In mammalian cells } \\
\text { transfected with FSH-R3, FSH has been shown not only to increase the influx of extracellular calcium, but also to stimulate cell } \\
\text { proliferation and ERK phosphorylation in a calcium-dependent fashion } \\
\text { FSH failed to stimulate cAMP accumulation in ID8 cells despite the presence of functional adenylate cyclase. Rather, FSH } \\
\text { stimulated ERK phosphorylation. After FSH addition, the phosphorylated forms of ERK1 and ERK2 were evident at } 10 \text { min, } \\
\text { elevated after } 30 \text { min and declined to basal levels after } 60 \text { min. } \\
\text { Pretreatment of cells with MEK inhibitor [PD98059, } 100 \mu \mathrm{MM} \text { ] abolished FSH mediated proliferation as well as cell signaling } \\
\text { Effects of calcium channel antagonist SNX-482 were assessed on ID8 MOSEC to determine FSH effect on influx of calcium via } \\
\text { voltage-gated channels. SNX-482 prevented FSH from stimulating both MOSEC growth and ERK activation }\end{array}$ \\
\hline Southern Blotting & $\begin{array}{l}\text { Oligonucleotide probes specific for Exons } 7 \& 11 \text { were used for Southern blot analysis of genomic DNA isolated from ID8 cells. } \\
\text { Hybridization analysis with both the probes recognized } 11.6 \text { and } 4.3 \mathrm{~kb} \text { fragments }\end{array}$ \\
\hline Northern Blotting & RNA blot using the same probes as above identified $1.9 \mathrm{~Kb}$ band \\
\hline Western Blotting & $\begin{array}{l}\text { Commercial antibody against FSHR (Santacruz) directed against an N-terminal sequence of the FSH-R recommended to } \\
\text { detect FSHR-1 was found to detect two bands of } 75 \text { and approximately } 50 \text { kDA which corresponded to FSHR-1 and FSHR-3 } \\
\text { respectively }\end{array}$ \\
\hline Immunocytochemistry & Surface expression of FSHR-3 and SNX-482 sensitive Cav2.3 channel in MOSEC was shown by immunocytochemistry \\
\hline
\end{tabular}

exist regarding the role of FSH in initiating ovarian cancer. FORKO mice develop ovarian cancers despite complete elimination of FSHR and lack of ovulation [17]. Another group reported that over-expression of FSHR is associated with development of ovarian epithelial cancer [18]. Li et al. [19] showed that rather than the canonical FSHR-1, alternately spliced FSHR-3 isoform mediated signaling promoted proliferation of mouse tumorigenic OSE cells ID8 by using multiple evidences at DNA, RNA and protein levels (Table 1).
We published an article in 2012 [20], where mice when treated with PMSG, exhibited marked proliferation of OSE cells on Day 2 and surprisingly large numbers of primordial follicles cohorts were observed in the cortical tissue on D7 after treatment (5-6 after PMSG compared to 1-2 cohorts in vehicle treated ovaries). Similar proliferation of OSE cells was also observed when mice were treated with $\mathrm{rFSH}$ [21]. These results of a direct action of PMSG/FSH on OSE cells intrigued us since it is widely believed that FSH acts on granulosa cells in the ovaries
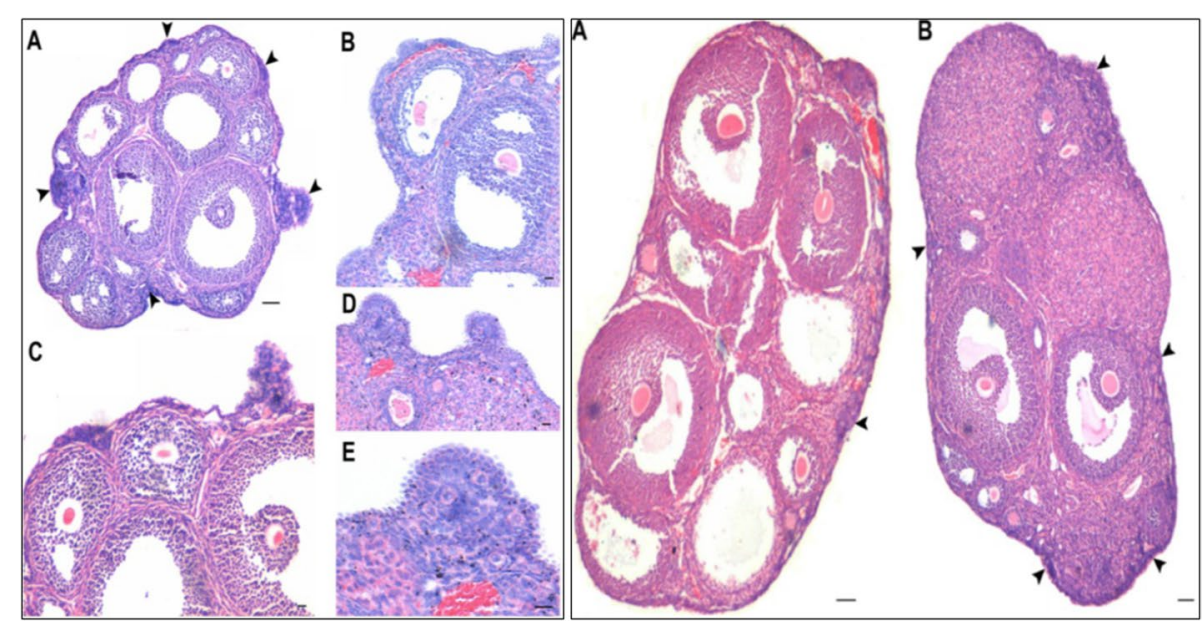

Fig. 1 FSH acts directly on ovary surface epithelium (OSE). H\&E-stained sections of mice ovaries after two (left panel) and seven (right panel) days of PMSG treatment (5 IU). Note proliferation of OSE (arrowheads) and small protuberances were prominent [Scale: A $100 \mu \mathrm{m}, \mathrm{B}-\mathrm{E} 20 \mu \mathrm{m}]$. Seven days later (right panel) increased cohorts of primordial follicles were observed just below the OSE [Scale: $100 \mu \mathrm{m}]$. Besides stimulating follicular growth, FSH stimulated OSE cells proliferation [20] 
and that initial follicular growth is gonadotropin independent [1] (Fig. 1).

These findings of FSH action on the OSE cells become more intriguing since ovarian stem cells are reported to reside in the OSE. Presence of stem cells in adult ovaries were initially reported by Tilly's group [22] in adult mice OSE and these stem cells can be enriched by gentle scraping of the OSE in several adult mammalian species including rabbit, marmoset, sheep, humans [23-26] and by enzymatic isolation of small-sized mice ovaries [27]. The stem cells are visualized as distinct spherical cells with high nucleo-cytoplasmic ratio with dark Hematoxylin-stained nuclei. Whereas epithelial cells are bigger in size with abundant, pink cytoplasm and pale stained nuclei (Fig. 2).

In a review describing various aspects of the ovarian stem cells [28], we have discussed that ovary harbors two populations of stem cells including $2-6 \mu \mathrm{m}$, very small embryonic-like stem cells (VSELs) and slightly bigger $6-8 \mu \mathrm{m}$ ovarian stem cells (OSCs). One may refer to published literature for further details on VSELs $[6-8,26]$. These stem cells differentiate in vitro into

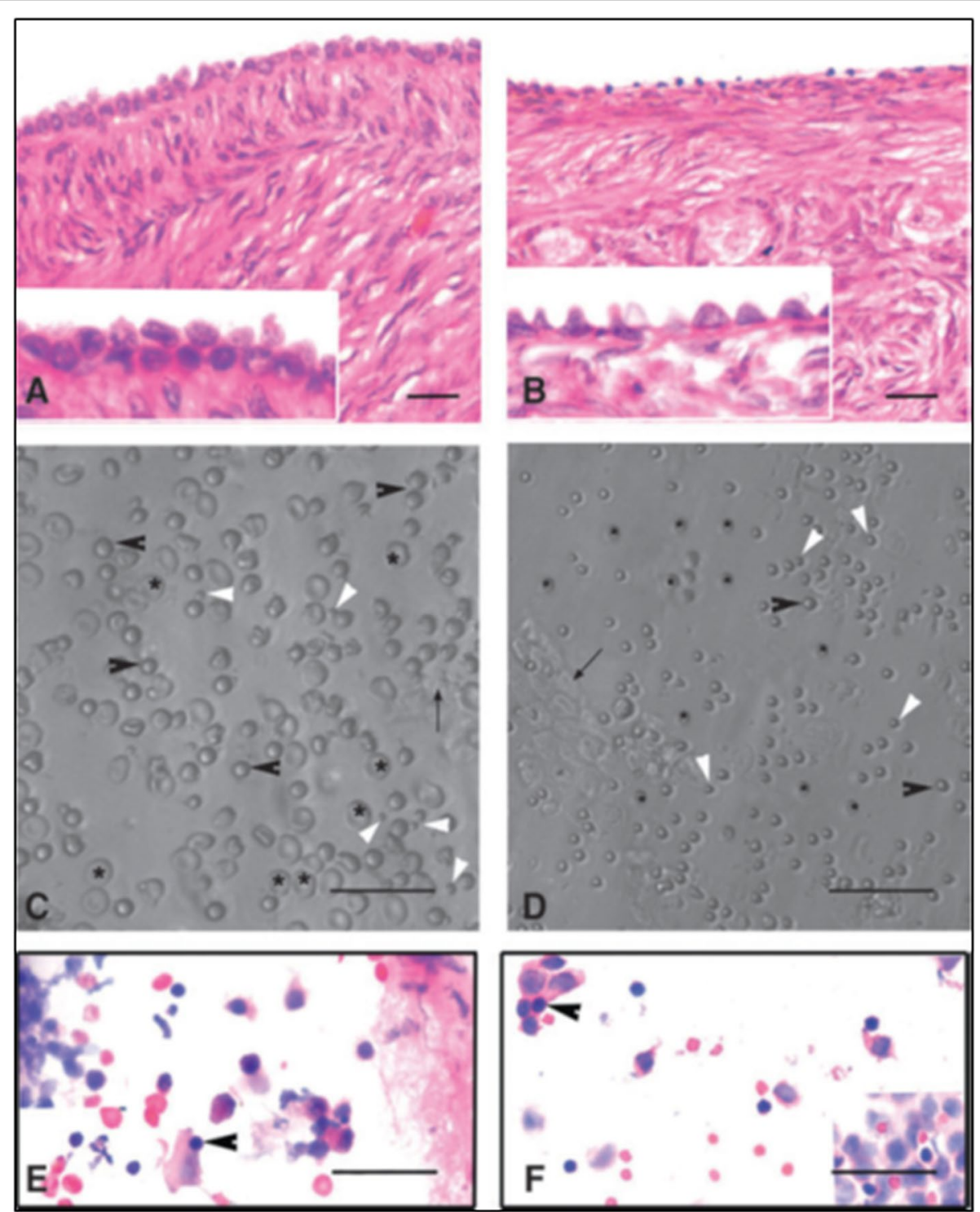

Fig. 2 Stem cells reside in adult ovary surface epithelium (OSE) A\& B. H\&E stained sections of menopausal human (left panel) and sheep (right panel) ovarian cortex. Note prominent OSE cells which were scraped and collected in a dish. C\& D. Note the presence of stem cells under Hoffman optics amongst OSE cells including small VSELS (white arrowhead), OSCs (black arrowhead) along with red blood cells (asterix). Epithelial cells with pale stained nuclei and abundant pink cytoplasm were also observed E \& F. Darkly stained, spherical stem cells in H\&E stained cell smears were clearly visualized (arrowheads) [23]. Scale: $20 \mu \mathrm{m}$ 
oocyte-like structures $[23,29]$, OSCs can be expanded over long periods in vitro and upon transplantation have resulted in live births [30-32] and also VSELs are increased in numbers in clinical samples of ovarian cancers [33-35].

Stem cells located in sheep OSE cells, collected by gentle scraping, were found to express FSHR (besides stem cell markers) whereas the epithelial cells remained distinctly negative (Fig. 3) [24]. Expression of FSHR exclusively on the stem cells and not on the epithelial cells was confirmed by immunocytochemistry (Fig. 3A), confocal microscopy (Fig. 3B) and by in situ hybridization (Fig. 3C, D). Evidently cancer cells in the ovary are not epithelial cells and neither arise by epithelial-mesenchymal transition as generally believed [36] but cancer represents excessive expansion of VSELs and OSCs residing in the OSE and tumorigenic ID8 cells most likely represent expanded cancer cells derived from the stem cells that reside amongst the ovary epithelial cells. The ovarian stem cells as well as the cancer cells that arise in the OSE express FSHR.

Immuno-localization studies were carried out further for FSHR expression in sheep ovarian sections as well as by confocal microscopy on sheep OSE cell smears (Fig. 4). FSHR expression was observed on both VSELs and OSCs. Co-expression of FSHR was also detected with a pluripotent stem cell marker SSEA-4. Cell surface expression of FSHR was clearly observed. The stem cells were also immuno-phenotyped for FSHR by flow cytometry. Two distinct populations of stem cells were distinctly observed undergoing asymmetrical, symmetrical divisions and clonal expansion (Fig. 4 B).

Effects of treating sheep OSE cells in vitro to FSH were also studied [24]. It was observed that stem cells expanded in numbers and formed increased numbers of germ cell nests (Fig. 5). Thus, FSH stimulates stem cells proliferation and clonal expansion. It was intriguing to note how stem cells story which was main focus of our
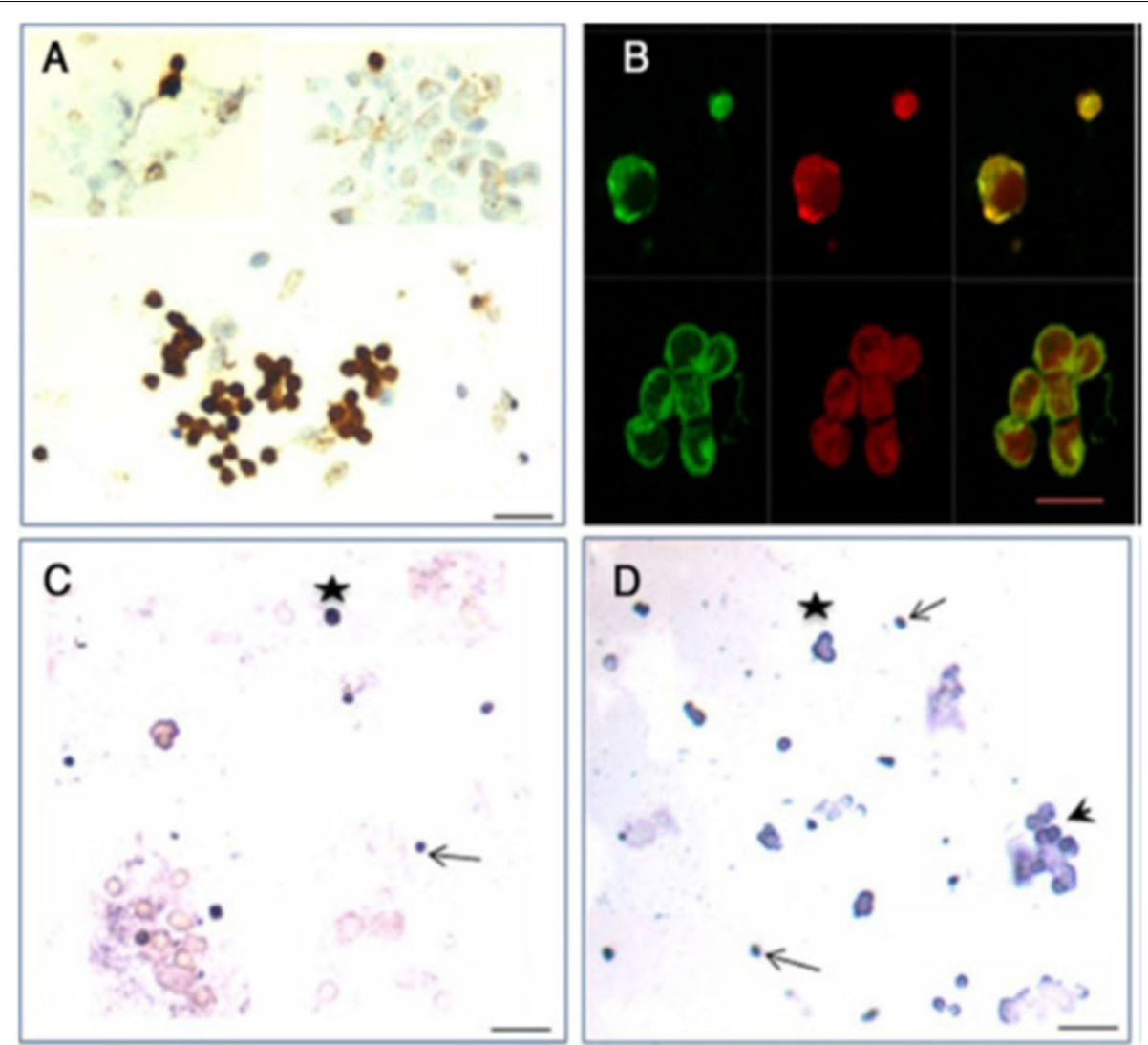

Fig. 3 FSHR expression on ovarian stem cells. A. Immuno-localization studies on OSE cell smears shows that only the stem cells express FSHR and epithelial cells remain distinctly negative. B. Immunofluorescence studies localized FSHR in small VSELs, slightly bigger OSCs and in a cluster of cells. In situ hybridization results using specific oligo probes showed expression of (C) Fshr-1 and (D) Fshr-3 transcripts on FSH treated sheep OSE smears. As evident Fshr-1 transcripts were observed in the nuclei of both VSELs (arrow) and OGSCs (asterix). Fshr-3 transcripts were localized both in the nuclei and cytoplasm and even in the germ cell nests 'cysts'. Presence of Fshr-3 in both cytoplasm and nuclei suggested active involvement of Fshr-3 transcript during FSH action on the stem cells [24]. Scale: $20 \mu \mathrm{m}$ 

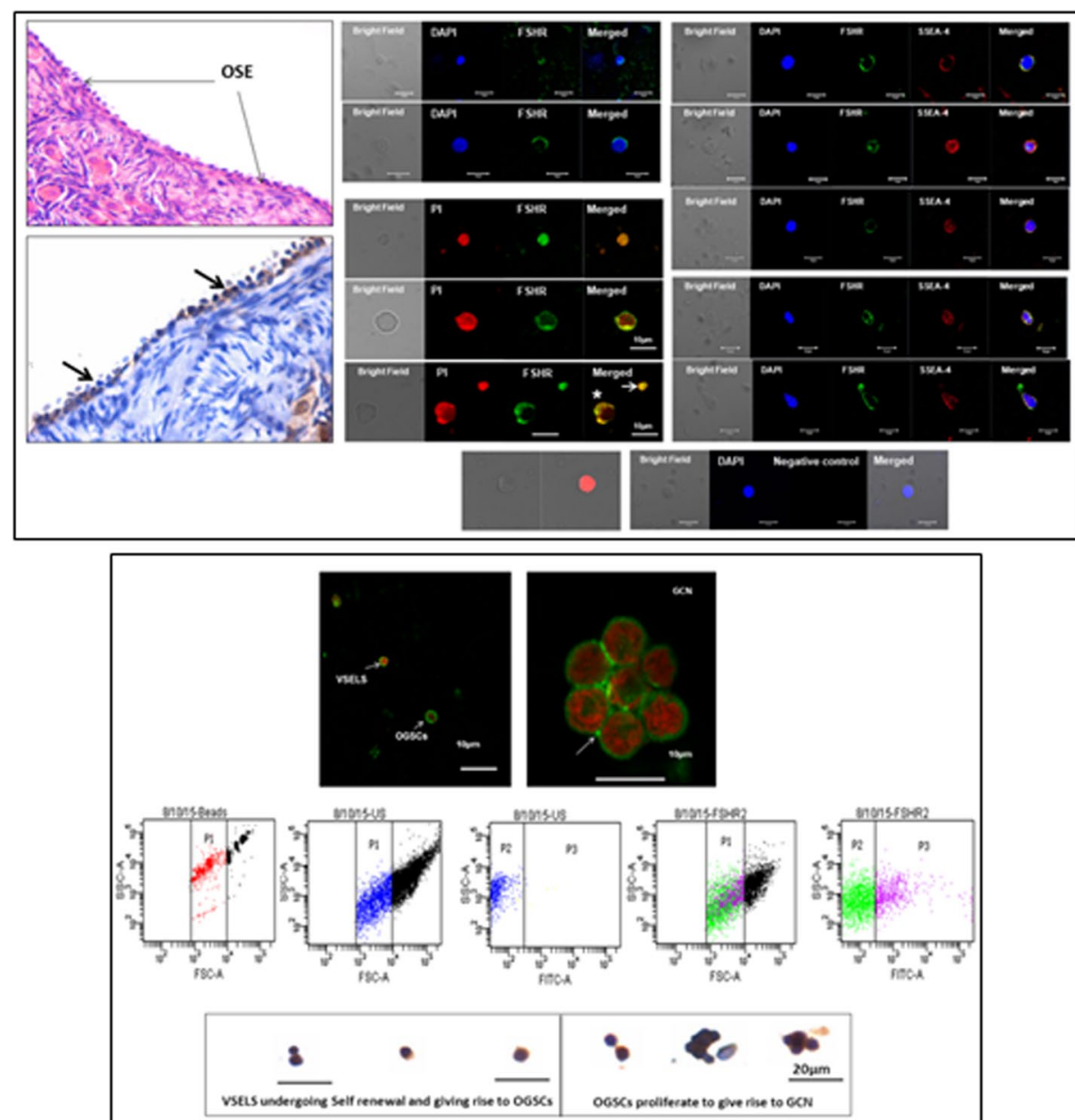

Fig. 4 Upper panel: Sheep ovarian sections on the left clearly show FSHR expression in the OSE. Stem cells isolated from sheep OSE expressed FSHR. Co-expression of FSHR with SSEA-4 (cell surface marker for pluripotent stem cells) was clearly evident confirming FSHR expression on the stem cells. Lower panel: FSHR expression on VSELs and OSCs and on a germ cell nest (multiple cells cluster with cytoplasmic continuity). 2-6 $\mu m$ cells were studied for FSHR expression by flow cytometry. Asymmetric, symmetric divisions and clonal expansion of stem cells is shown [24, 25]

lab research gradually got intertwined with FSH-FSHR biology. Further experiments revealed that when sheep OSE cell smears (Fig. 5) were treated in vitro with FSH, greater numbers of germ cell nests were observed compared to untreated controls after 15h (Fig. 5B compared to C). Thus, it was clearly evident that FSH stimulated the stem cells to undergo proliferation and clonal expansion. qRT-PCR studies were undertaken to further analyze change in Fshr-1 and Fshr-3 expression after $3 \mathrm{~h}$ and $15 \mathrm{~h}$ in these cultures in 3 different experiments (Fig. 6).

Later on, Parte et al. [37] studied the effect of bFGF and FSH on human ovarian cortical tissue biopsies in culture (Fig. 7). As evident, both treatments resulted in increased expression of pluripotent (Oct-4A, Nanog), germ cells (tOCt-4, c-Kit, Vasa) and transition (Gdf9, Lhx-8, Amh) specific transcripts. This was again suggestive of stimulatory effect of FSH on ovarian stem cells.
Other groups have also reported FSHR isoforms in mammalian ovaries, human ovarian cancer tissue and cancer cell lines. Sullivan et al. [38] reported that Fshr3 is the pre-dominant isoform in different types (small, medium, large and preovulatory) of follicles in sheep ovaries. Gerasimova et al. [39] detected FSHR isoforms in $35 \%$ of cases associated with abnormal ovarian response. Zhou et al. [40] cloned FSHR2 (with deletion of exon 10 and inclusion of 2 small exons after exon 9) and FSHR3 (exon 10 is deleted, had exons 1-6) isoforms in human OSE cells obtained from a patient who underwent surgery because of a cyst. These isoforms were also detected in human follicular fluid of 30 patients undergoing IVF. Perales-Puchalt et al. [41] reported FSHR expression on aggressive ovarian carcinoma samples. Mamas et al. [42] reported that alternately spliced variants of FSHR may be associated with poor or high response to exogenous FSH. 


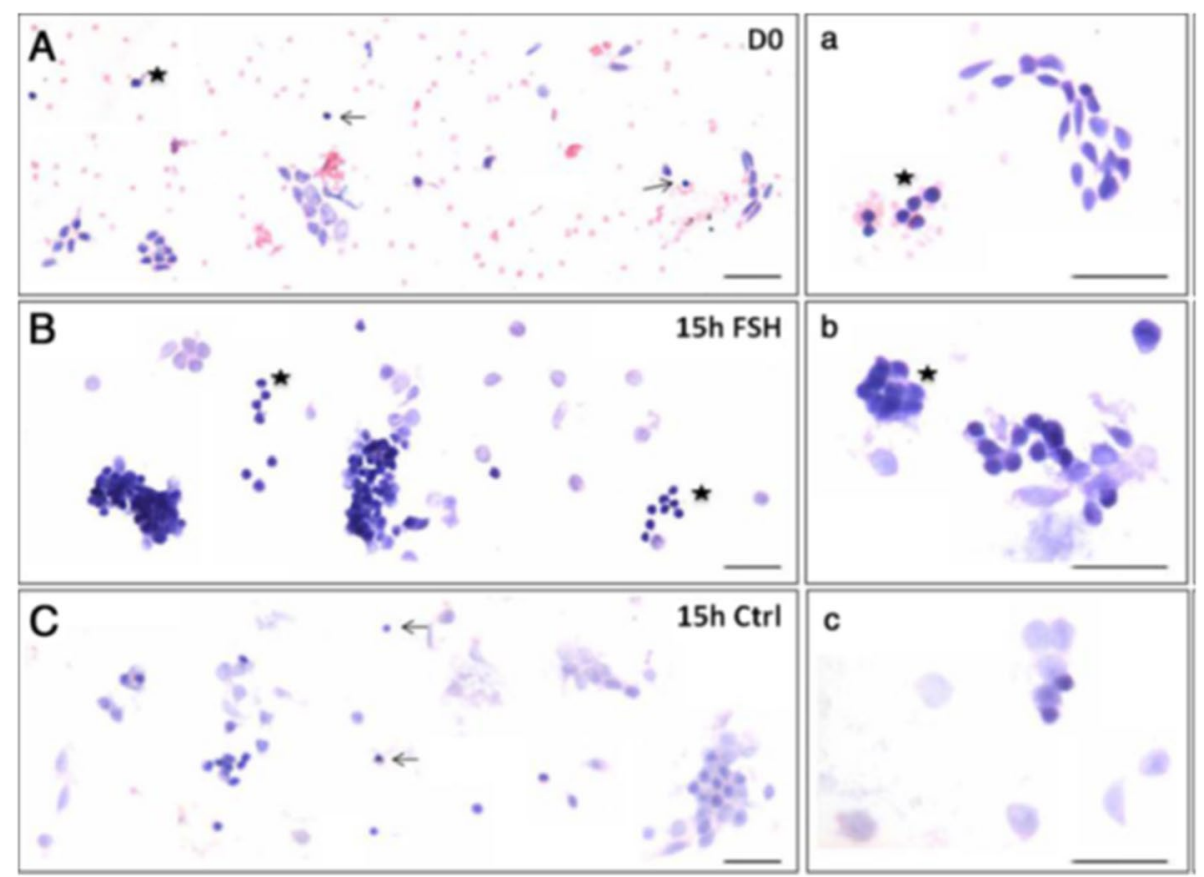

Fig. 5 Effect of FSH treatment on the ovarian stem cells located in the ovary surface epithelium. A\&a Freshly prepared sheep OSE smear after $\mathrm{H}$ \& E staining. Epithelial cells (spindle-shaped cells with pale nuclei and abundant cytoplasm) and distinct populations of darkly-stained putative stem cells including the VSELs (arrow) and OSCs (asterisk) were evident along with red blood cells (RBCs) B\&b Stem cells and germ cell 'cysts' were increased after $15 \mathrm{~h}$ of FSH treatment. The nests represent clonal expansion of stem cells with incomplete cytokinesis C\&c OSE smear after $15 \mathrm{~h}$ culture without FSH. Scale: $20 \mu \mathrm{m}$ [24]

Karakaya et al. [43] showed presence of FSHR isoforms in women who were poor responders to FSH treatment. None of the splice variants could initiate cAMP signaling despite high FSH doses. Song et al. [44] studied FSH induced proliferation of epithelial ovarian cancer cells is not mediated via cAMP suggesting a possible involvement of Fshr-3 rather than the canonical Fshr-1 by activating sphingosine kinase.

Fshr-3 transcripts have been detected in mice OSE cells and not canonical Fshr-1 [45]. Studies were undertaken on 4 weeks old mice after 30 days of treatment with cyclophosphamide $(100 \mathrm{mg} / \mathrm{kg}$ body weight for first 2 days) and busulphan ( $10 \mathrm{mg} / \mathrm{kg}$ body weight for 4 days). This treatment resulted in complete loss of follicles but flow cytometry studies showed the presence of VSELs in chemoablated ovaries (Fig. 8) [27]. Treatment of chemoablated mice with PMSG (5IU) and flow cytometry after $48 \mathrm{~h}$ showed further increase in VSELs numbers (control ovaries: $0.02 \pm 0.01 \%$; chemoablated ovaries: $0.03 \pm 0.02 \%$; PMSG treatment: $0.08 \pm 0.03 \%)$. The chemoablated ovaries were removed and cultured in vitro with and without FSH (5mIU) for 7 days and later studied for the effect of FSH on stem cell markers and proliferation was marked by studying BrdU uptake. An increased expression of stem/progenitor cells (Oct-4A,
Sca-1, Oct-4, Dazl) was observed along with proliferation in OSE evidenced by BrdU uptake. This was accompanied by the formation of germ cell nests (positive for BrdU, MVH and SSEA-1) and expression of Scp3 which was not detected in chemoablated ovaries without FSH treatment [27].

To conclude, stem cells residing in the mouse, rabbit, marmoset, sheep and human ovarian surface epithelium express FSHR. Besides acting on the granulosa cells, FSH acts directly on the ovarian stem cells and stimulates them to undergo proliferation, asymmetrical, symmetrical divisions and clonal expansion to form germ cell nests and this action is mediated via Fshr3 in mice, sheep and human ovaries. This is entirely a new and novel FSHFSHR biology within the mammalian ovaries and delineated by our group for the first time. FSHR are expressed on the OSE cells, to be more precise on the stem cells that reside in the OSE whereas the epithelial cells remain distinctly negative. Since cancer involves selective expansion of stem cells, FSHR has been reported on ovarian cancer stem cells. FSH acts via Fshr-3 on the stem cells via ERK/MAPK to bring about proliferation of stem cells.

FORKO mice discussed above [17] developed ovarian cancer despite absence of ovulation is intriguing. Incessant ovulation and repeated damage to the OSE possibly 


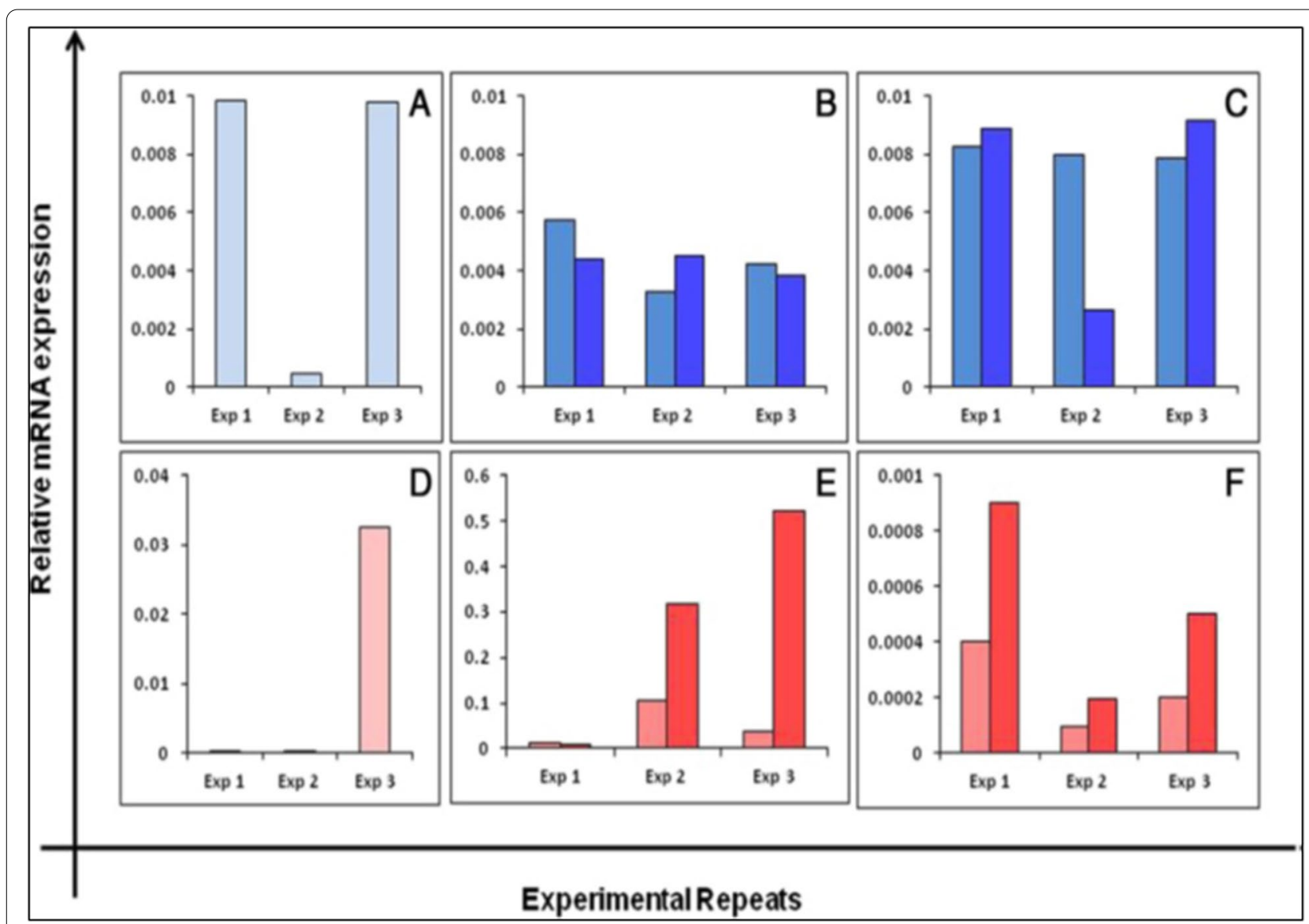

Fig. 6 Differential expression of Fshr-1 (upper panel) and Fshr-3 (lower panel) transcripts in sheep OSE cells after treating with FSH. Fshr-1 transcripts (dark blue bars) in vitro after 0, 3 and 15 h or without (light blue bars) FSH treatment (A-C). Evidently Fshr-1 was not affected by FSH treatment. Whereas Fshr-3 after FSH (red bars) showed upregulation compared to without FSH (pink bars) treatment. Expression of Fshr-3 was maximal after $3 \mathrm{~h}$ (please note a change in Y-axis scale to appreciate a difference between (D-F). The relative expression levels of each transcript from three different experiments are represented individually [24]. These results of FSH action on normal sheep OSE cells via Fshr-3 in vitro are similar to those reported for tumorigenic cell line ID8 and discussed above in Table 1 [19]

does not initiate cancer. VSELs express FSHR and are easily mobilized and initiate ovarian cancer in presence of increased FSH thus supporting Gonadotropin theory of ovarian cancer as we discussed earlier [19]. However, direct evidence to support the concept that although FORKO mice lack FSHR, VSELs expressing FSHR are mobilized from other tissues to the ovaries and initiate cancer remains to be generated. Virant-Klun's group has reported increased numbers of VSELs in clinical samples of ovarian cancer (33-35).

\section{Testicular stem cells}

FSHR isoforms have been reported in sheep [46] and humans [39, 47] testes as well as on human testicular germ cell tumors [48, 49]. Similar to ovaries, pluripotent VSELs exist along with the spermatogonial stem cells (SSCs) in the adult human [50] and mice [51, 52] testes. Testicular VSELs are relatively quiescent similar to ovarian VSELs and survive chemoablation in mice [51, 52] and various oncotherapy regimens in human testes $[53,54]$.

We have recently reported a simple and robust protocol to enrich both the populations of stem cells from mice testes along with their detailed characterization [55]. FSHR expression was studied in normal testes and after 30 days of busulphan treatment $(25 \mathrm{mg} / \mathrm{Kg})$ with and without FSH treatment (10IU per day for 2 days) and PMSG (10IU per day for 2days) [52]. VSELs survived chemotherapy and increased in numbers after FSH treatment and this was also confirmed by flow cytometry [52]. Men with idiopathic infertility stand to benefit by FSH treatment as suggested by Simoni's group [3] probably because FSH directly acts on the tissue-resident stem cells and promotes spermatogenesis. FSHR expression was studied on adult mouse testicular stem cells by immuno-fluorescence using two different commercial 


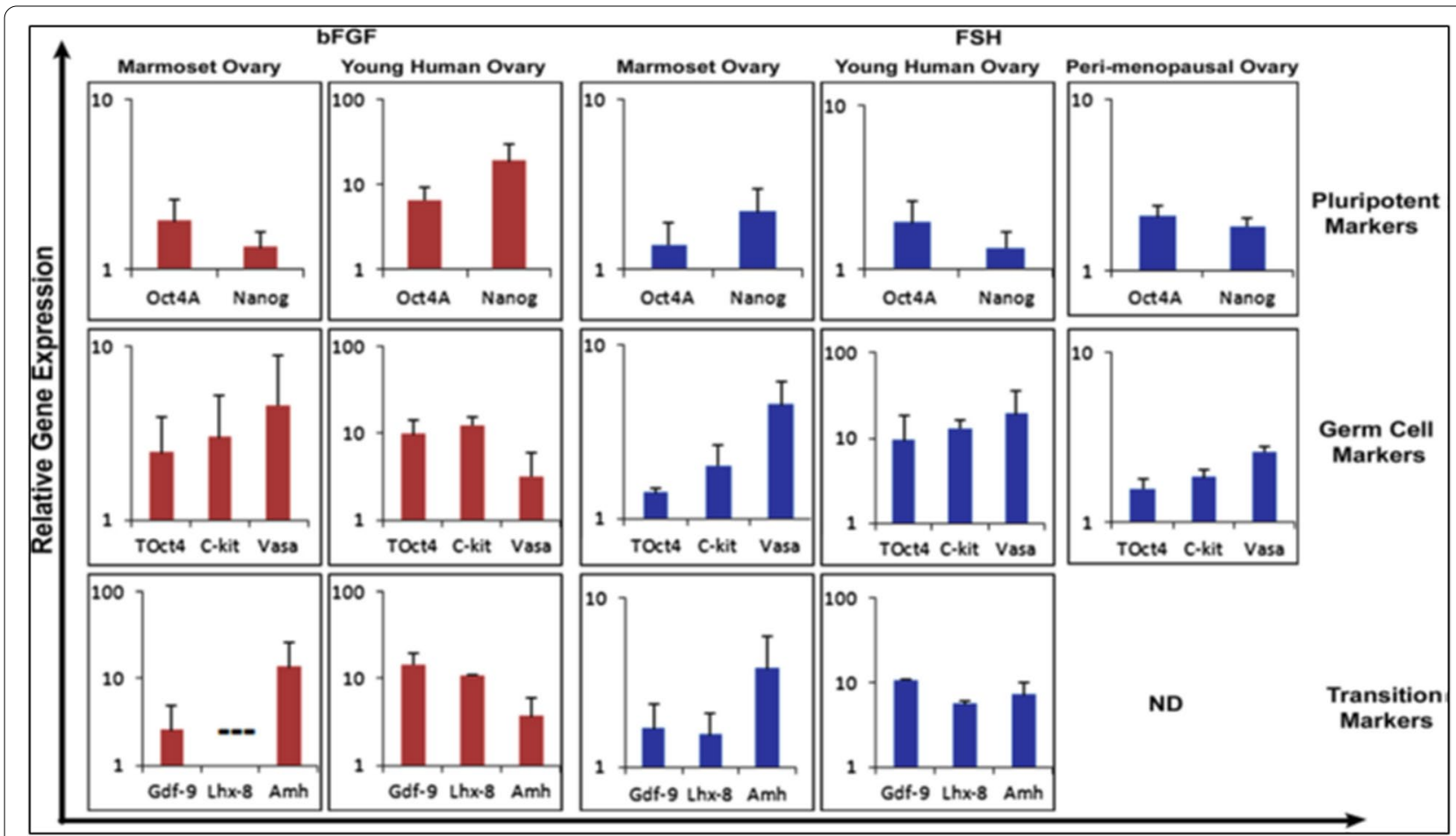

Fig. 7 Effect of bFGF $(100 \mathrm{ng} / \mathrm{ml})$ and FSH $(0.5 \mathrm{IU} / \mathrm{ml})$ treatment on stem cells (Oct-4A, Nanog), germ cells (Oct-4, c-Kit, Vasa) and transition (Gdf9, Lhx-8, Amh) specific transcripts in ovarian cortical tissue culture of marmoset and human ovarian tissue [37]

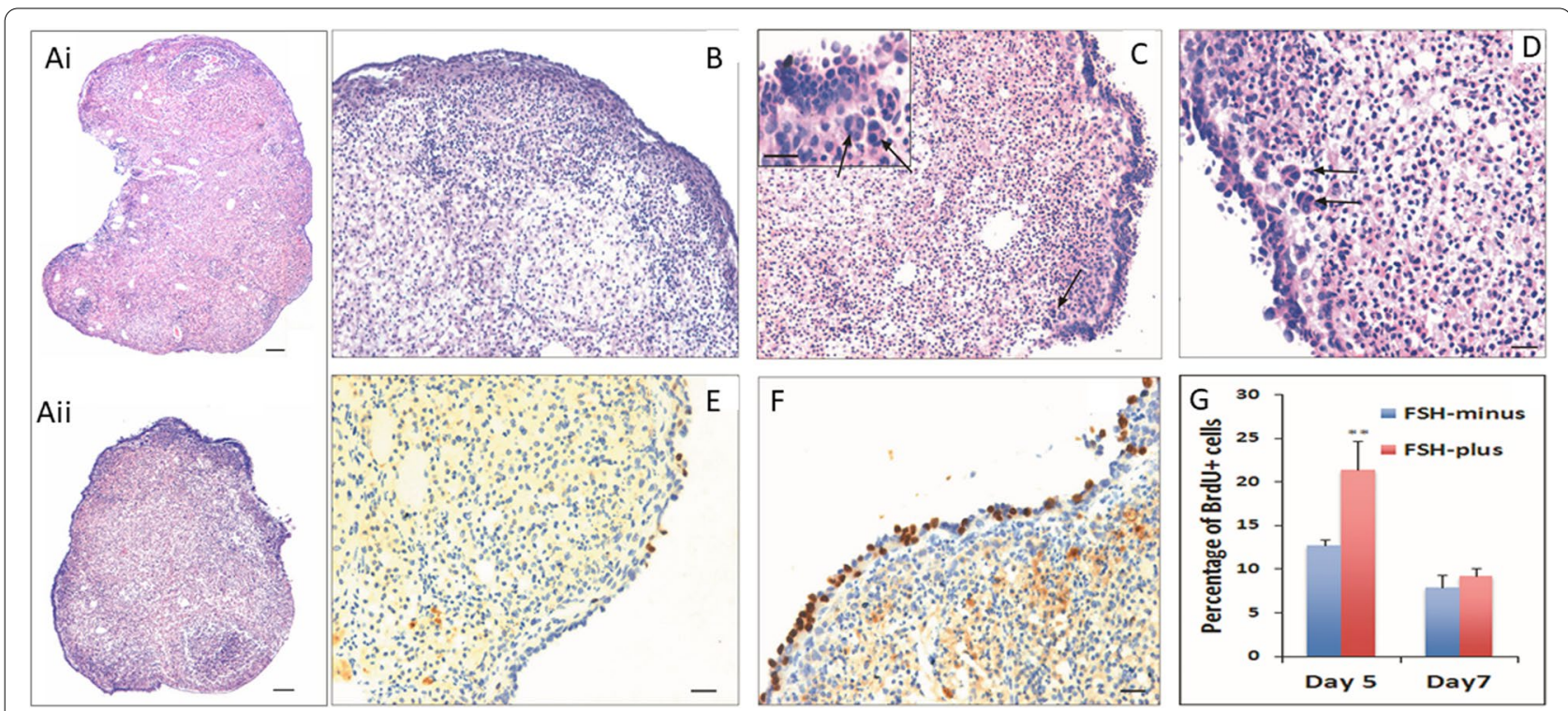

Fig. 8 Effect of FSH on chemoablated mouse ovary. Right panel: H\&E-stained sections of intact mice ovaries after 7 days culture in FSH-minus (upper) and FSH-plus 10mIU (lower) group. Note extensive proliferation of OSE cells in FSH-plus group. Left panel, Upper images are H\&E stained sections at higher magnification showing multilayered OSE in FSH-plus group. Lower images show increased BrdU uptake in FSH-plus group compared to FSH-minus group. Percent BrdU positive cells were much more in FSH treated group on D5 [25]. Scale: $20 \mu \mathrm{m}$ 
antibodies (Abcam, Santacruz), by Western blot, in situ hybridization using oligoprobes specific for Fshr1 and Fshr3 and by qRT-PCR. Fshr-1 and Fshr-3 expression was also studied in mice testes neonatally exposed to endocrine disruption with estradiol $(20 \mu \mathrm{g} / \mathrm{pup} /$ day on days $5-7)$ and diethylstilbestrol $(2 \mu \mathrm{g} / \mathrm{pup} /$ day on days 1-5) [55]. Twenty-four hours of treatment to both intact (PMSG 10IU, Fig. 9) and chemoablated (4weeks after busulphan $25 \mathrm{mg} / \mathrm{kg}$, FSH $10 \mathrm{IU}$, Fig. 10) mice testes were studied [52]. FSH exerted a distinct effect on the stem/ progenitor cells confirmed by increased expression of PCNA and OCT-4.

Testicular stem cells smears were prepared from chemoablated testes. Fig. 11 shows differential expression of OCT-4 in testicular stem cells, being nuclear in the pluripotent VSELs (A \& B) and cytoplasmic in SSCs (C \& D). SCA-1 positive stem cells co-expressed OCT-4 (F) and also SCA-1 positive stem cells co-expressed FSHR [52]. These stem cells also express ER $\alpha$ and $\operatorname{Er} \beta$ and thus are directly modulated by FSH and are vulnerable to endocrine disrupting chemicals which are mostly synthetic estrogens [55]. FSHR expression was observed on testicular stem cells using two different commercially available antibodies (Abcam, Santacruz,
Fig. 10). Besides omission of primary antibody as negative control, we also used immunizing peptide to confirm specificity of FSHR expression (Fig. 11). Effect of treatment with FSH (10 IU) for $24 \mathrm{~h}$ was studied on the stem cells in normal and chemoablated testes.

As shown in Fig. 12 (upper panel), VSELs in the size range of $2-6 \mu \mathrm{m}$ with a surface phenotype of LINCD45-SCA-1+ were detected in chemoablated testes and their numbers increased from 1.8 to $4.5 \%$ upon treating chemoablated mice with FSH. Immuno-phenotyping studies were also undertaken to study OCT4, PCNA and FSHR in normal and chemoablated testes after treatment with rFSH (10 IU). Lower panel shows rFSH (10IU) treatment effects on stem cells in chemoablated testes which led to increased numbers of OCT-4 positive stem cells which underwent proliferation (PCNA positive cells increased) and led to increased numbers of FSHR expressing stem/progenitor cells. Thus, similar to in ovaries, in testes also FSH stimulates tissue-resident stem cells.

Further Western blotting experiment on proteins extracted from Sertoli cells and intact testes after FSH treatment when hybridized with Abcam FSHR antibody showed presence of $75 \mathrm{kDa}$ band for canonical FSHR-1

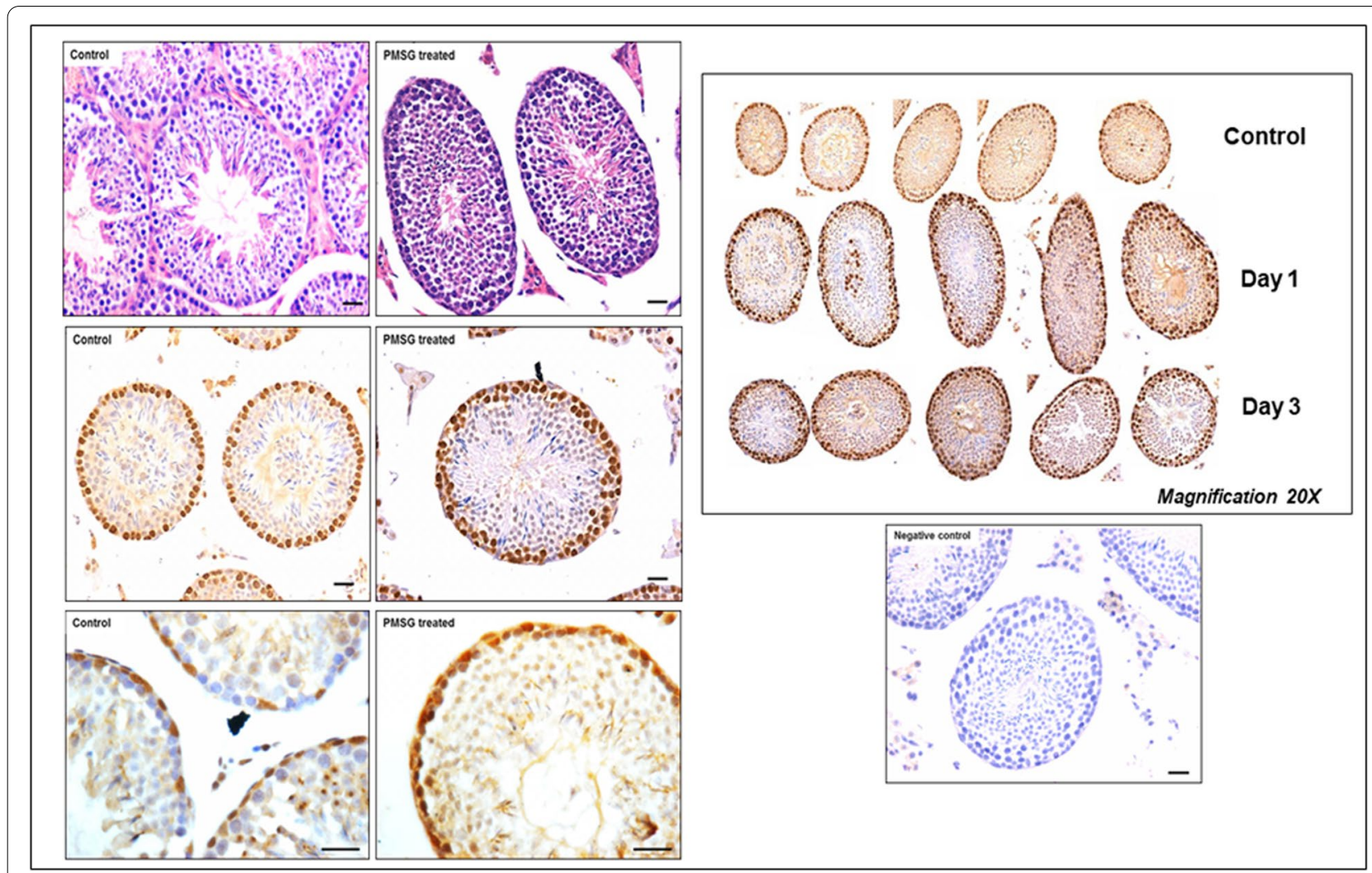

Fig. 9 Mice treated with PMSG (10IU) showed increased numbers of germ cells in H\&E-stained sections. This was confirmed by increased PCNA and OCT-4 expression. PCNA expression was studied after 24 and $72 \mathrm{~h}$ and increased numbers of germ cells was clearly evident [52]. Scale: $20 \mu \mathrm{m}$ 

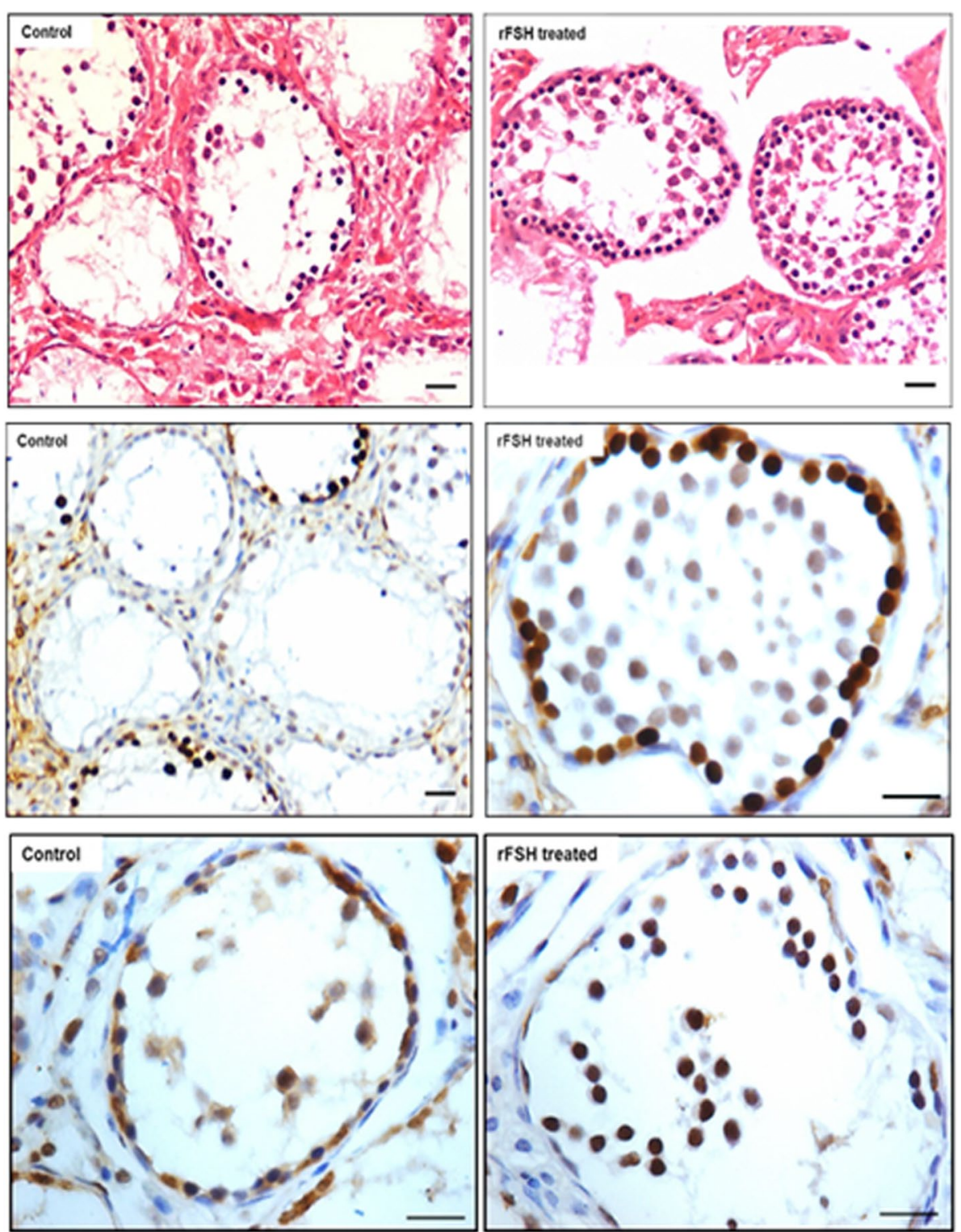

Fig. 10 Mice were treated with busulphan $(25 \mathrm{mg} / \mathrm{Kg}$ ) and one month later treated with FSH (10 IU) resulted in increased numbers of germ cells.as evident in H\&E stained sections associated with increased expression of PCNA and OCT-4 [52]. Scale: $20 \mu \mathrm{m}$

in Sertoli cells but in intact testis, two bands of 75 and $40 \mathrm{KDa}$ were detected. $75 \mathrm{kDa}$ band was not detected in intact testes after FSH treatment because as such the protein amount may be too less but we clearly observed the band in protein extracted from Sertoli cells. However, FSH treatment affected stem/progenitor cells and FSHR-3 and other isoforms showed increased expression and were detected by Western blot (Fig. 13).

Expression of FSHR on the stem cells was also confirmed by in situ hybridization using oligoprobes. Both Fshr-1 and Fshr-3 were found expressed on the stem cells. FSH treatment resulted in active transcription of Fshr-3 on dividing stem cells compared to Fshr-1 mRNA (Fig. 14).

Expression of Fshr1 and Fshr3 were also studied by qRT-PCR in different treatment groups (Fig. 15). It was clearly observed that alternatively spliced Fshr-3 was markedly regulated compared to Fshr-1 in various treatment conditions [52]. Single-cell suspensions (including both Sertoli cells and germ cells) obtained after enzymatic digestion, from both intact and chemoablated testes was cultured in DMEM/F-12 medium containing $10 \%$ 


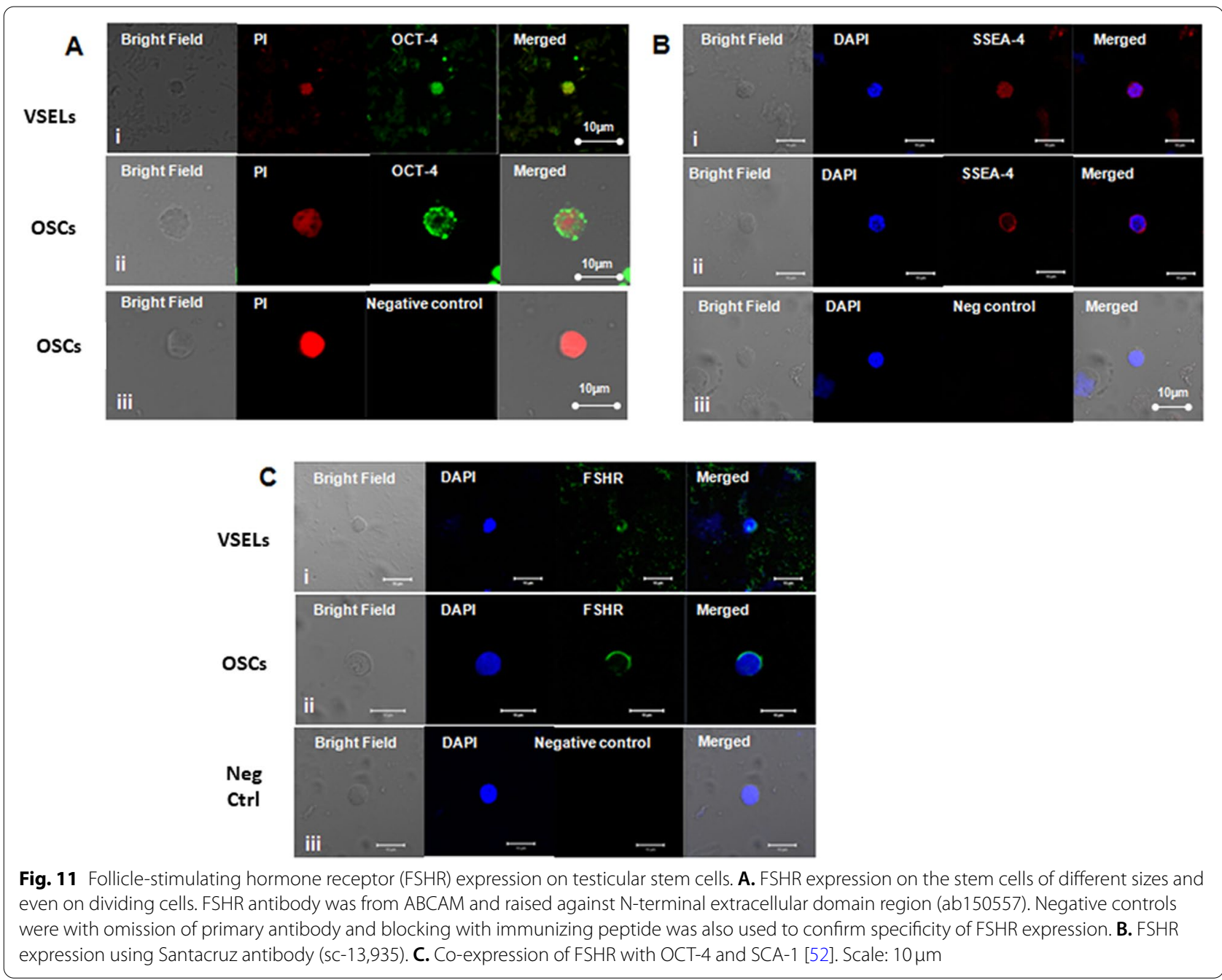

FBS and antibiotics with and without $\mathrm{rFSH}(5 \mathrm{IU} / \mathrm{mL})$ for $24 \mathrm{~h}$. Cells were harvested $24 \mathrm{~h}$ later for qRT-PCR studies. Sertoli cells were separated by differential plating. For this, testicular cells were plated in $60 \mathrm{~mm}$ culture dishes, Sertoli cells get attached whereas the germ cells remain floating and are removed by gentle change in medium. Sertoli cells were allowed to grow to $70 \%$ confluence, treated with FSH (5IU) for $3 \mathrm{~h}$, and then harvested for qRT-PCR studies. Magnetic enrichment of SCA-1-positive cells from chemoablated testes was carried out using FITC conjugated SCA-1 antibody and EasySep kit (Stem Cell Technology, Vancouver, Canada). Stem cell antigen 1 (SCA-1) positive cells were plated in a $35 \mathrm{~mm}$ culture dish and incubated overnight with and without FSH $(5 \mathrm{IU} / \mathrm{mL})$. Cells isolated from intact and chemoablated (enriched for quiescent VSELs as all actively dividing cells are destroyed by chemotherapy) testes were put in culture and studied for Fshr expression after $24 \mathrm{~h}$ in vitro. Note $>100$ fold increase in Fshr-3 in cells collected from chemoablated testes upon treatment with PMSG (10 IU). Sertoli cells also responded to FSH treatment and both Fshr-1 ( $>8$ fold) and Fshr-3 ( $>16$ fold) transcripts were upregulated. SCA-1 sorted cells showed $>80$ fold increase in Fshr-3 compared to minimal increase in Fshr1. Fshr-3 was the more predominant transcript through which FSH exerts its action on the testicular stem cells and also on Sertoli cells.

In a recent study, mice pups were exposed to estradiol $(20 \mu \mathrm{g} / \mathrm{pup} /$ day on days $5-7)$ or diethylstilbestrol $(2 \mu \mathrm{g} /$ pup/day on days 1-5) and later studies were undertaken on D100 of adult life. Treatment affected the testicular stem cells and resulted in pathologies including disrupted spermatogenesis, reduced sperm counts, infertility and tumor-like changes were observed in DES treated group [56]. Expression of Fshr1 and Fshr3 was studied on D100 by qRT-PCR (Fig. 16). Fshr-3 was markedly upregulated after both estradiol and DES treatment whereas canonical Fshr-1 expression remained unaffected. DES treatment 


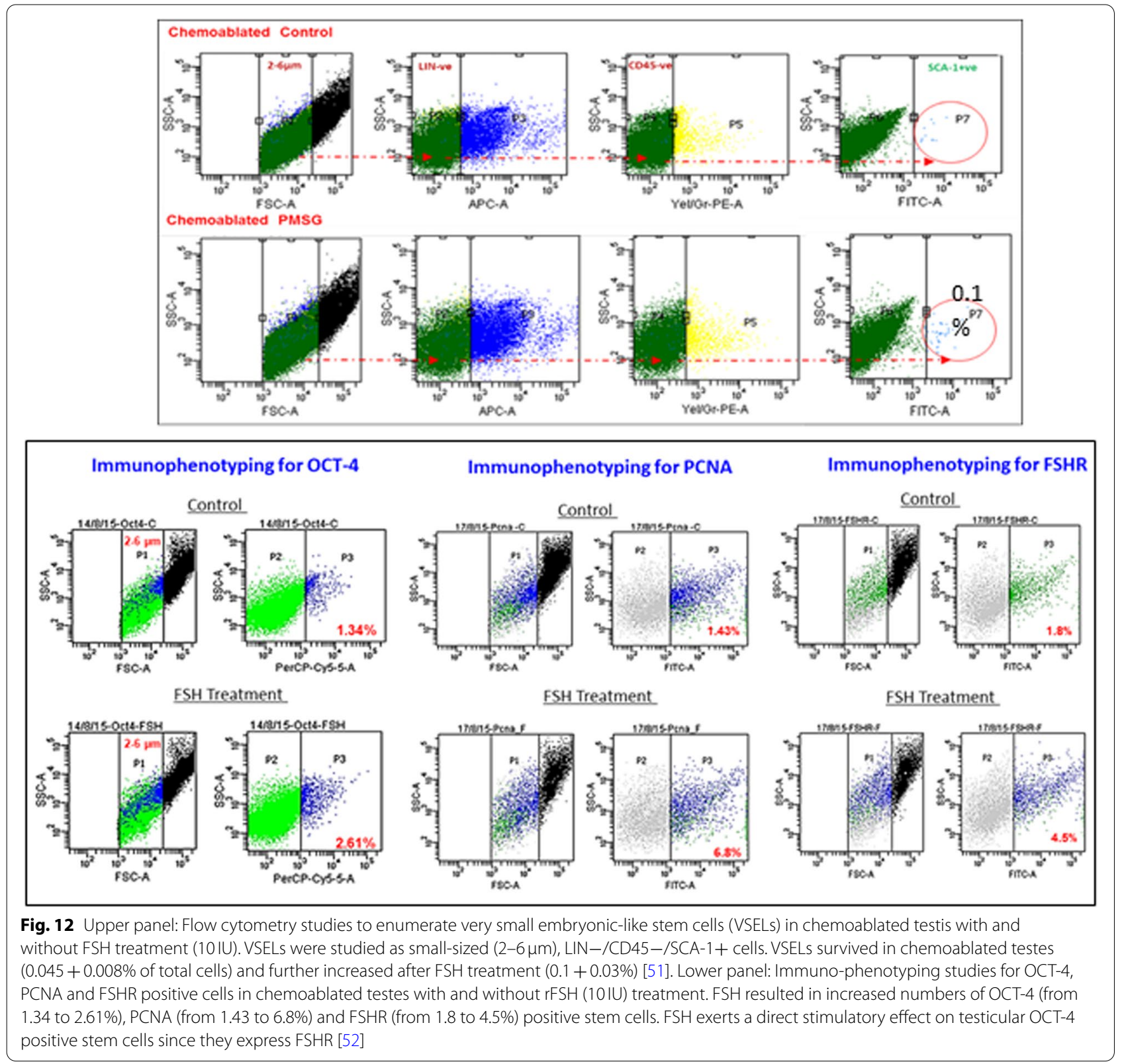

resulted in cancer-like changes in the testes accompanied with marked up-regulation of Fshr-3 ranging from 15 to 100 folds [56]. In two samples after DES treatment, $>800$ folds increase in Fshr-3 transcripts was observed but was not included in Fig. 15 since the $\mathrm{Ct}$ value $>35$.

The results compiled above are intriguing since FSHR expression is expected only on the Sertoli cells as per existing understanding [1]. Results suggest a direct action of FSH on the testicular stem cells. Similar to ovaries, in testes also, FSH directly stimulated the stem cells to undergo ACD, SCD and clonal expansion [52, 57]. More than 40 folds increase in Fshr-3 in DES treated testes with cancer-like changes along with increased expression of embryonic markers including Oct-4A ( $>10$ folds) [56] which is a specific and sensitive marker for testicular cancer [58].

\section{Uterine stem cells}

Uterus is considered as an end organ for the steroid hormones estrogen $(\mathrm{E})$ and progesterone $(\mathrm{P})$ to act. These hormones are secreted by the ovaries under the influence of pituitary gonadotropins and thus it is generally believed that FSH exerts an indirect effect on the uterus. However, few reports have challenged this existing dogma 

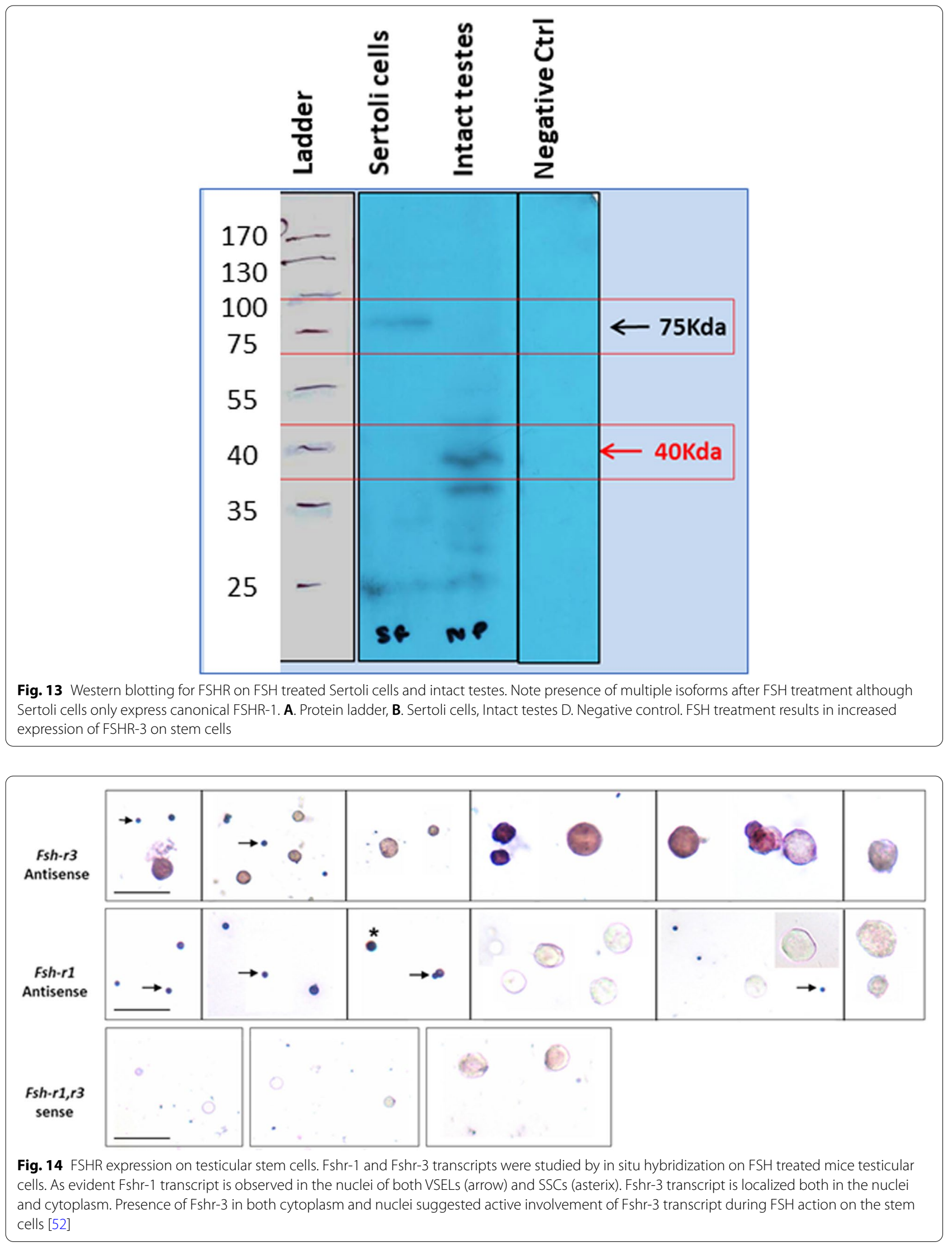


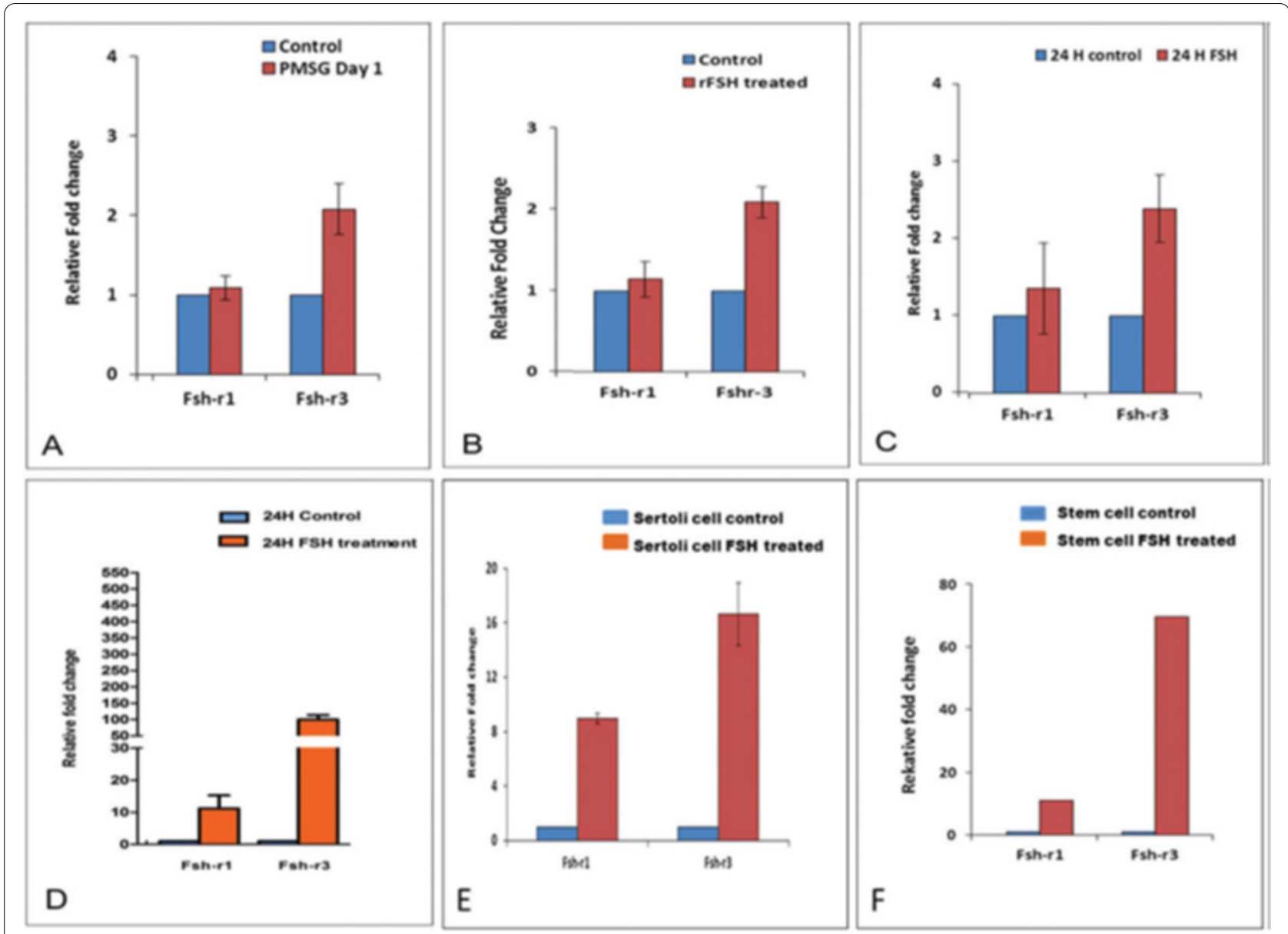

Fig. 15 Effect of FSH treatment on alternatively spliced Fshr-1 and Fshr-3 transcripts by qRT-PCR under different experimental conditions. Various treatment groups showed higher upregulation of Fshr-3 compared to canonical Fshr-1, which was minimally regulated. Intact (PMSG 10 IU) (A) and chemoablated (rFSH $10 \mathrm{IU})$ (B) testis and total cells isolated from intact (C) and chemoablated (D) testis. Note $>100$-fold increase in Fshr3 in cells in vitro from chemoablated testis. Sertoli cells also respond to FSH treatment, and both Fshr-1 (> 8 fold) and Fshr-3 (>16 fold) transcripts are upregulated. SCA-1 sorted cells showed $>80$ fold increase in Fshr3 compared to minimal increase in Fshr-1. Fshr-3 appears to be the more predominant transcript through which FSH exerts its action on the stem cells [52]

in the field. Increased expression of FSHR was reported in the secretory phase human endometrium compared to proliferative phase $[59,60]$. Later FSHR expression was reported in human uterus and placenta. Stilley et al. [61] reported FSHR on the endothelial cells of blood vessels in the endometrium, myometrium, and cervix; endometrial glands of the proliferative and secretory endometrium; cervical glands and the cervical stroma; and in stromal cells (at low levels) and muscle fibers of the myometrium in non-pregnant women. During pregnancy, placental FSHR was detected by $8-10$ weeks of gestation up to term on the endothelial cells in fetal portions of placenta and umbilical cord; epithelial cells of the amnion; decidualized cells surrounding the maternal arteries in the maternal decidua; and the stromal cells and muscle fibers of the myometrium, with particularly strong expression at term. Moreover, genetically modified mice lacking Fshr in fetal portions of the placenta revealed adverse effects on fetoplacental development [61]. Robin et al. [62] reported FSHR expression on endometriotic tissue by immunohistochemistry studies. Ponikwicka-Tyszko et al. [63] reported functional expression of FSHR in endometriotic lesions. FSHR is reported in uterine myomas also [64]. This body of literature is looked at with disbelief by others $[9,11]$ who are perplexed by this extragonadal expression of FSHR. But results are true, only more efforts are required to interpret and understand them.

Our group has reported two populations of stem cells including VSELs and slightly bigger EnSCs in adult mouse uterus and recently published a robust protocol to enrich them from mice uterus [65]. VSELs survive in the atrophied uterus of bilaterally ovariectomized mice and effects of treatment with physiological levels of hormones were reported on the uterine VSELs/EnSCs [66]. Also, 

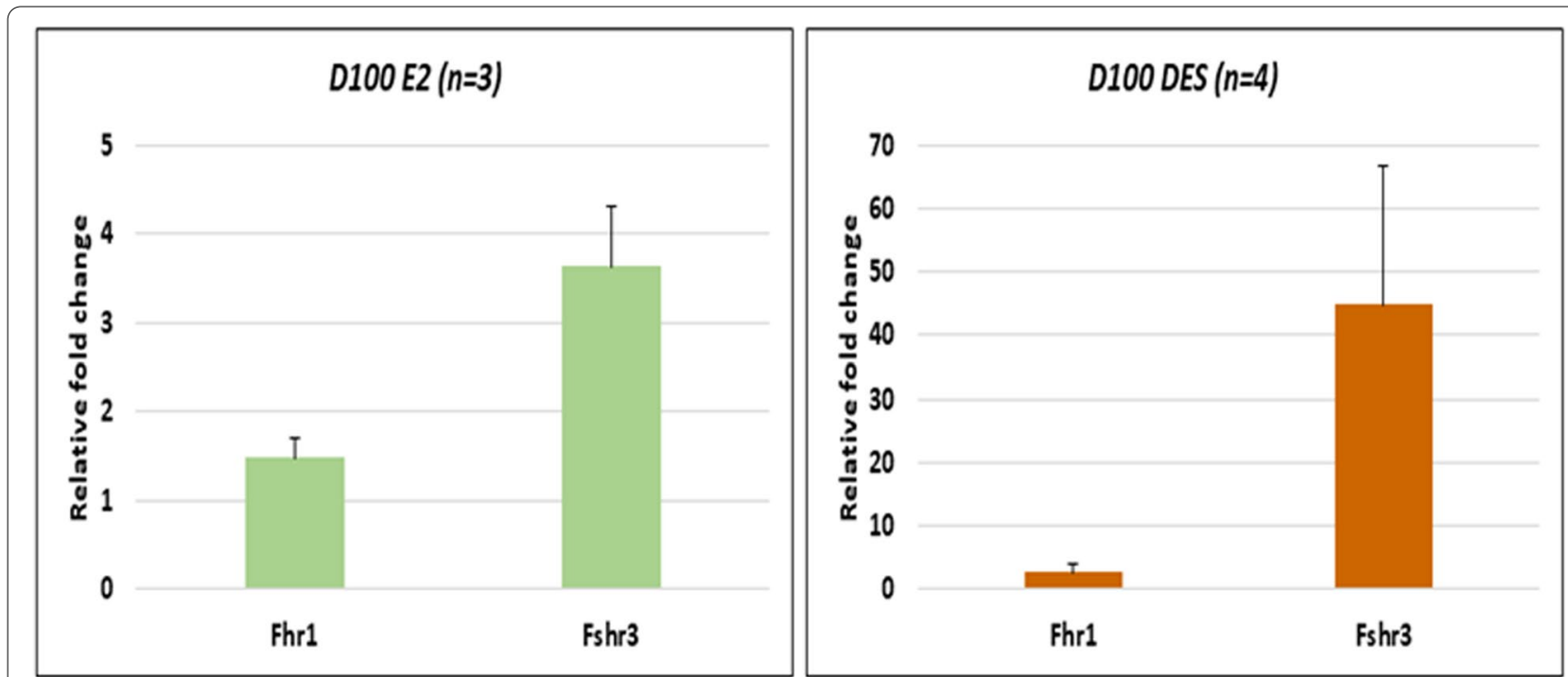

Fig. 16 Fshr-1 and Fshr-3 expression in 100 days old testes of mice neonatally exposed to estradiol (E2, 20 Mg/pup/day on days 5-7) and diethylstilbestrol (DES, $2 \mu \mathrm{g} /$ pup/day on days 1-5). Both treatments resulted in increased numbers of stem cells and their blocked differentiation. However, marked increase in Fshr-3 was noted after DES which resulted in testicular cancer-like changes. Cancer occurred due to excessive self-renewal of VSELs which expressed FSHR-3 [unpublished data, related to 56]. Data represents mean \pm se

effects of treatment with estradiol, progesterone and FSH on both myometrium [67] and endometrium [68] were reported but here discuss the effects of only FSH treatment (5IU/day for 7 days) on both the myometrium and endometrium.

Myometrium was atrophied after bilateral ovariectomy and both perimetrium and myometrium were clearly visualized in the ovariectomized uterus along with small spherical stem cells (Fig. 16, arrow). FSH treatment stimulated the myometrium and large numbers of cells were visualized which expressed both PCNA as well as OCT-4. At higher magnification, small spherical OCT-4 positive VSELs were clearly visualized in the myometrium along with mesenchymal progenitors with cytoplasmic OCT-4. At higher magnifications, the small spherical cells were clearly visualized (Fig. 17, red broken circle) in both the perimetrium and myometrium along with progenitors with cytoplasmic OCT-4. These findings are intriguing since they demonstrate a direct effect of FSH on the stem/progenitor cells residing in the myometrium.

A careful scrutiny of the H\&E stained sections of atrophied endometrium (Fig. 18) after bilateral ovariectomy also showed the presence of small spherical cells with dark stained nuclei, which probably are the VSELs that survive ovariectomy. Expression of PCNA and OCT-4 was studied in the atrophied endometrial sections. As evident few cells with distinct nuclear PCNA expression and cells with both nuclear and cytoplasmic OCT-4 were observed.
FSH treatment exerted a marked effect on the endometrial epithelial cells which showed hypertrophy and hyperplasia (Fig. 19). Small spherical VSELs were observed cut in different planes of sections and at places appeared to be dividing (broken circle). Thus, FSH appeared to exert a direct effect on the epithelial cells and on the uterine stem cells. Hyperplasia was confirmed by studying PCNA expression which remained nuclear (Fig. 20). Small clusters of cells and singly existing stem cells were observed positive for PCNA. The small spherical cells also expressed nuclear OCT-4 whereas the epithelial cells expressed cytoplasmic OCT-4. This relationship of nuclear OCT-4 and cytoplasmic OCT-4 in stem and epithelial cells shows the hierarchy amongst various cell type and pluripotent stem cells with nuclear OCT-4 differentiate into epithelial cells with cytoplasmic OCT-4.

Uterine stem cells can be enriched by spinning at $1000 \mathrm{~g}$ and visualized after $H \& E$ staining [65]. The stem cells have been well characterized, express embryonic markers and ER, PR and FSHR (Fig. 20A). RT-PCR showed presence of pluripotent transcripts Oct-4A along with Fshr1, Fshr3, Ero, PR (Fig. 20B). Surprisingly all the 4 alternately spliced isoforms of FSHR were detected in the uterus by Western blotting (Fig. 21).

The stem cells enriched from adult uterus were used to prepare smears and studied for expression of PCNA and FSHR (Fig. 22). Two distinct stem cells populations including small VSELs (red arrow) and slightly bigger EnSCs (black arrow) were clearly visualized. 

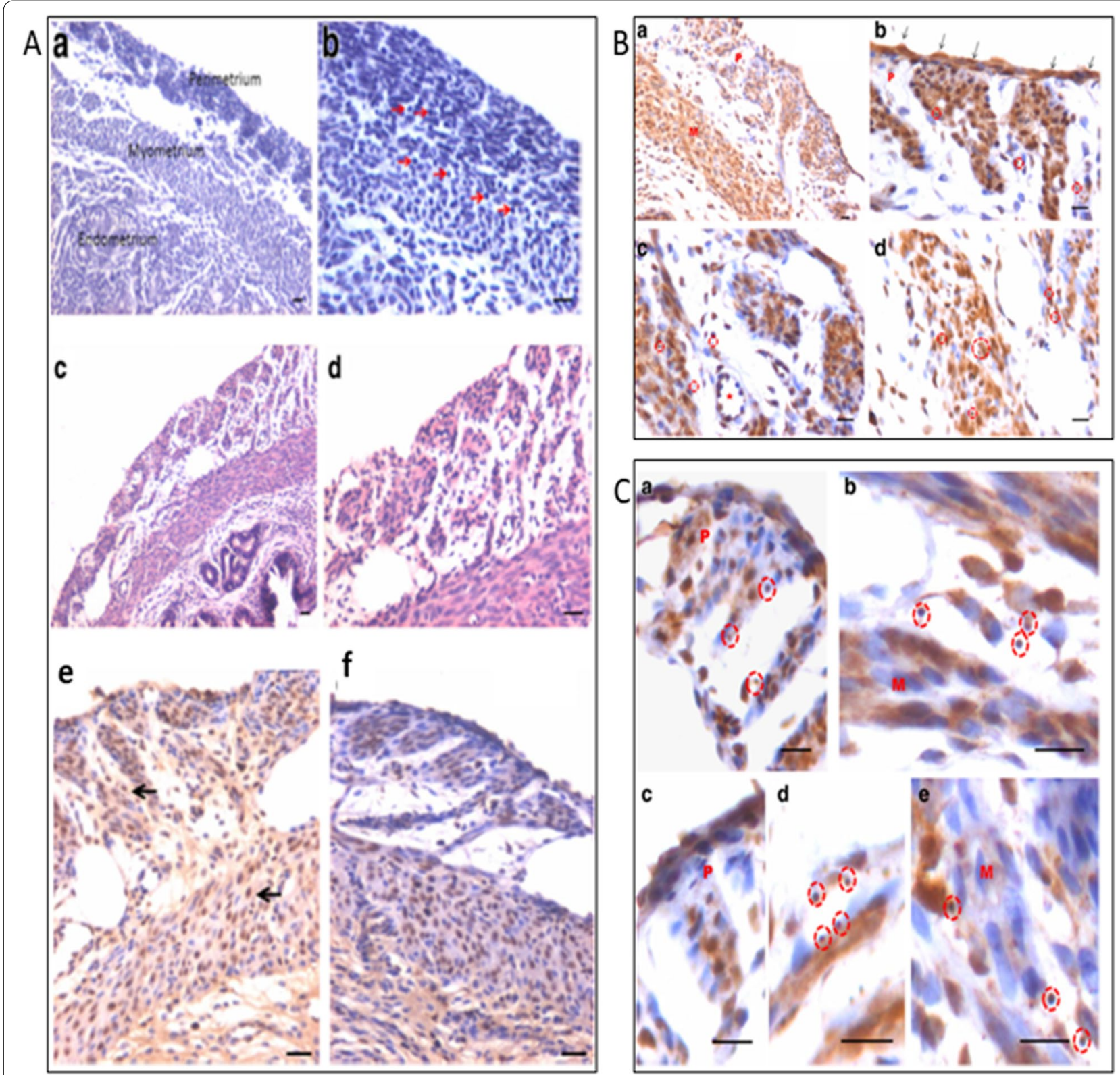

Fig. 17 Uterine myometrium in adult mice after 5 days of FSH treatment to bilaterally ovariectomized mice. $\mathbf{A}$ a\&b: Myometrium of bilaterally ovariectomized mice with small spherical stem cells (red arrows) c, d: After 5 days of FSH treatment e,f: PCNA expression in FSH treated group. B a-d: OCT-4 expression in FSH treated myometrial sections. Note presence of small, spherical cells expressing FSHR and OCT-4. C a-d: Higher magnification showing small spherical cells with nuclear OCT-4. Note bigger myometrial 'progenitor' cells with cytoplasmic OCT-4 [67]. Scale: $20 \mu m$

The cells undergo asymmetrical (red broken circle), symmetrical (blue broken circle) divisions and clonal expansion (blue asterix). These divisions were also observed at higher magnifications (Fig. 22, bottom panel).

To conclude, two populations of stem cells exist in adult mouse uterus which express FSHR and FSH exerts direct effect on the uterine stem cells similar to in the ovaries and testes. Early differentiating progenitors express embryonic markers as well as FSHR. We have recently shown that neonatal endocrine disruption affects uterine stem cells differentiation and progenitors increase in numbers associated with increased FSHR expression [69]. Moreover, various pathologies like endometriosis, fibroids and endometrial cancers express increased FSHR because they arise due to affected differentiation and selective expansion of FSHR and OCT-4 positive stem/ progenitor cells. 

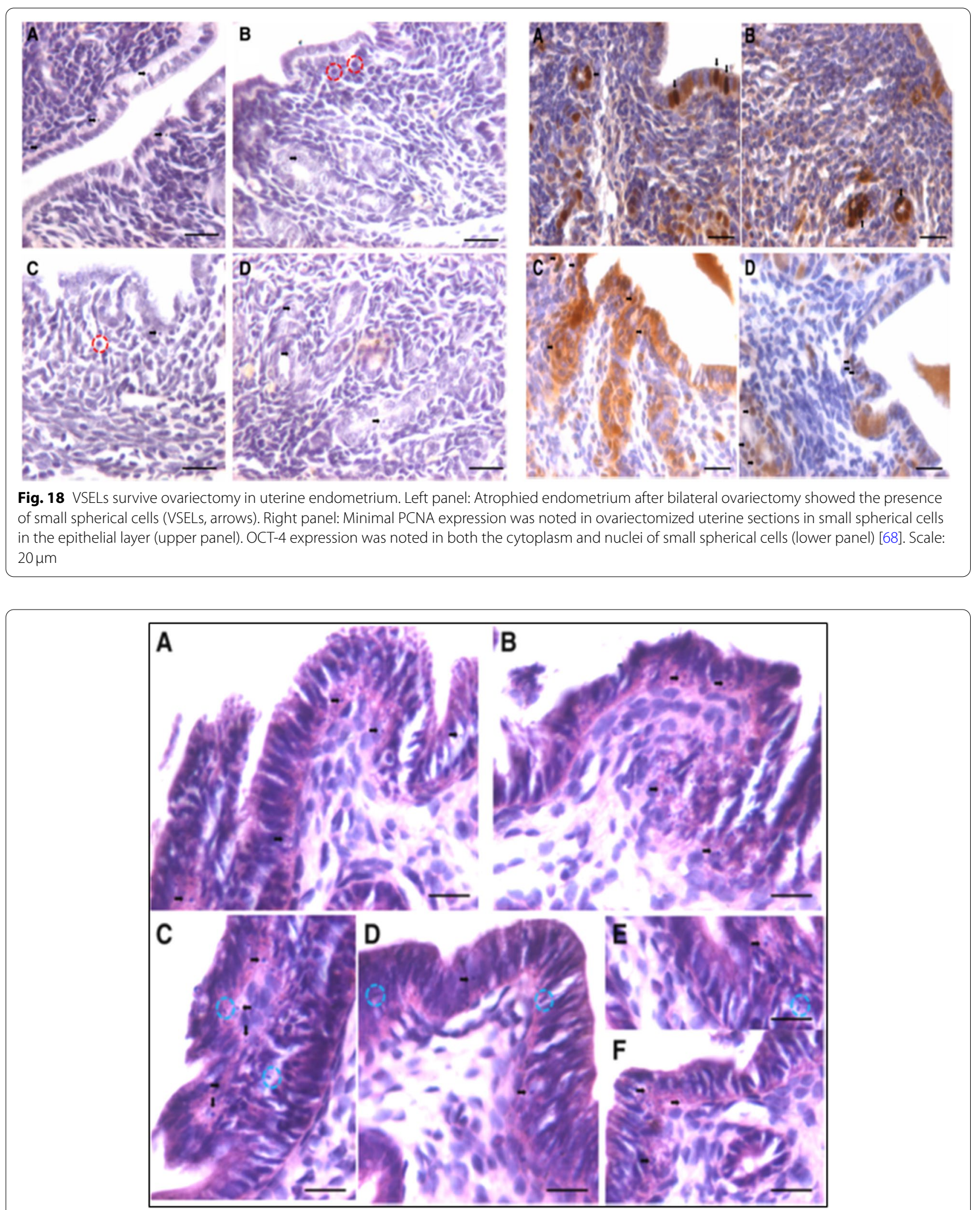

Fig. 19 FSH exerts direct effect on the endometrial epithelial cells and the stem cells. FSHR treatment for 5 days exerted a marked effect on the endometrial epithelial cells which showed both hyperplasia and hypertrophy. Note the presence of small spherical cells which are the VSELs cut in different plains of sections. They also appeared to be dividing at few places (broken circles) [68]. Scale: $20 \mu \mathrm{m}$ 

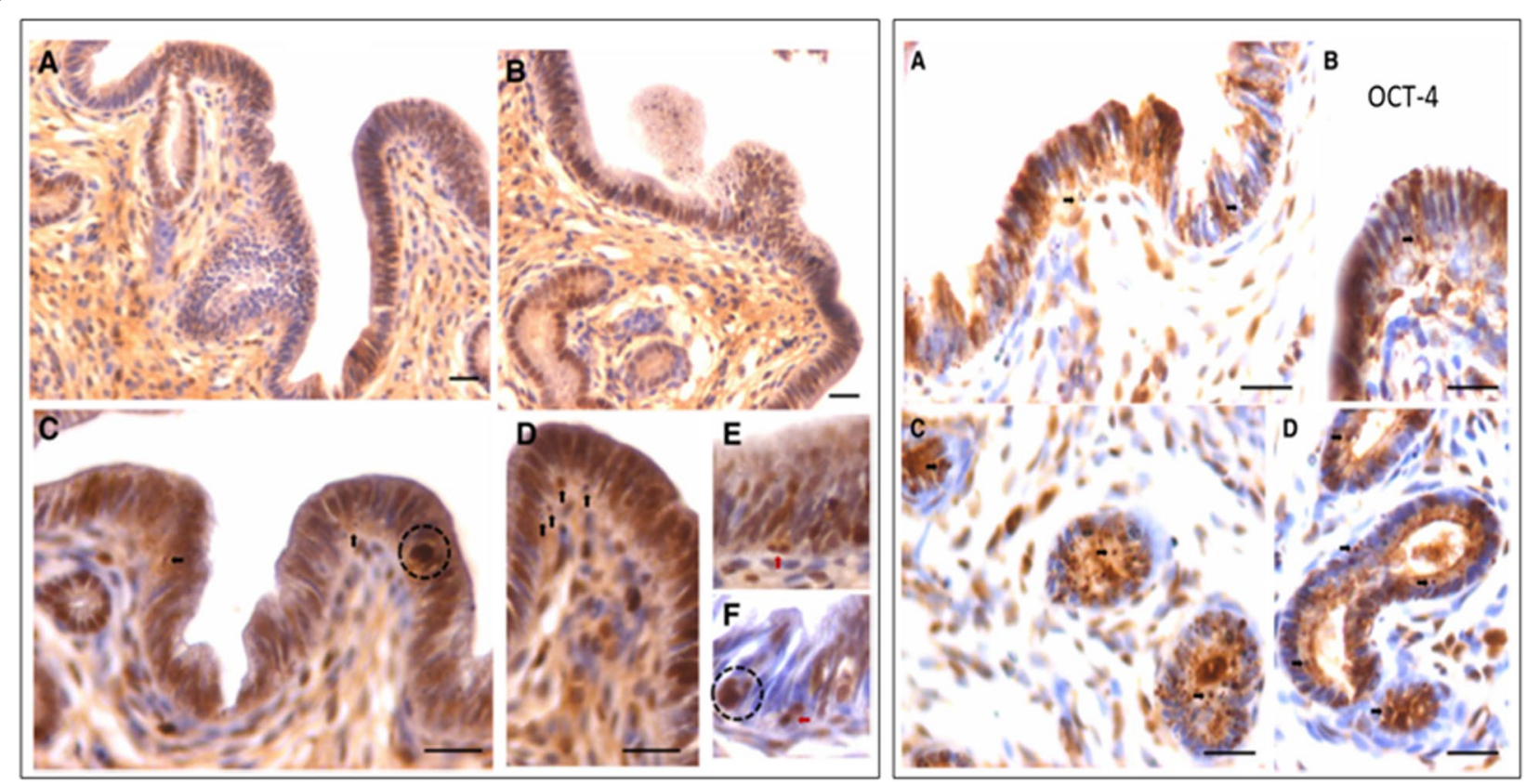

Fig. 20 Left panel: Hyperplasia of epithelial cells was confirmed by nuclear expression of PCNA after FSH treatment. Stem cells also expressed PCNA (arrows). Small clusters of cells also expressed PCNA (broken circle in C, F). Right panel: Small spherical cells also expressed nuclear OCT-4 whereas the epithelial cells expressed cytoplasmic OCT-4 [68]. Scale: $20 \mu \mathrm{m}$
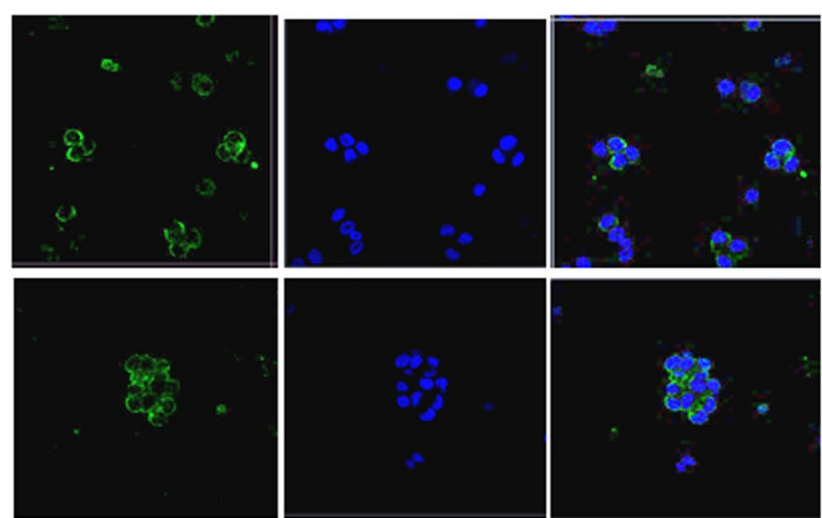

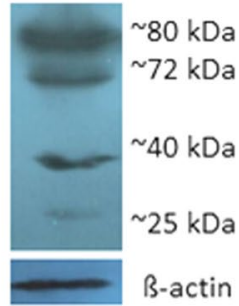

FSHR2: $~ 80 \mathrm{kDa}$ FSHR1: $72 \mathrm{kDa}$ FSHR3: $40 \mathrm{kDa}$ FSHR4: $25 \mathrm{kDa}$

Fig. 21 Left panel: FSHR expression on mice uterine stem cells. Right panel: Stem cells in adult mouse uterus express embryonic markers, Fshr1, Fshr3, ER alpha and PR [65]. Western Blot showed presence of 4 alternately spliced FSHR isoforms in adult mouse uterus [68]

\section{Bone marrow stem cells}

Hematopoietic system also harbors two populations of stem cells including VSELs and hematopoietic stem cells (HSCs) [7, 70], although there is no consensus as yet. Evidence has accumulated over time that hematopoietic stem cells share several markers with the germline and that treatment with prolactin, androgens, and estrogens stimulate hematopoiesis. Ratajczak's group [71] for the first-time reported expression of functional FSH and $\mathrm{LH}$ receptors on hematopoietic stem cells and VSELs and also on embryonic stem cells and teratocarcinoma cells [12]. Our group also reported expression of functional FSHR on bone marrow VSELs and HSCs in adult mice [72]. Abdelbaset-Ismail et al. [73] reported expression of receptors at both mRNA and protein levels, for FSH, luteinizing hormone, prolactin, progesterone, estrogen, and androgen on hematopoietic 

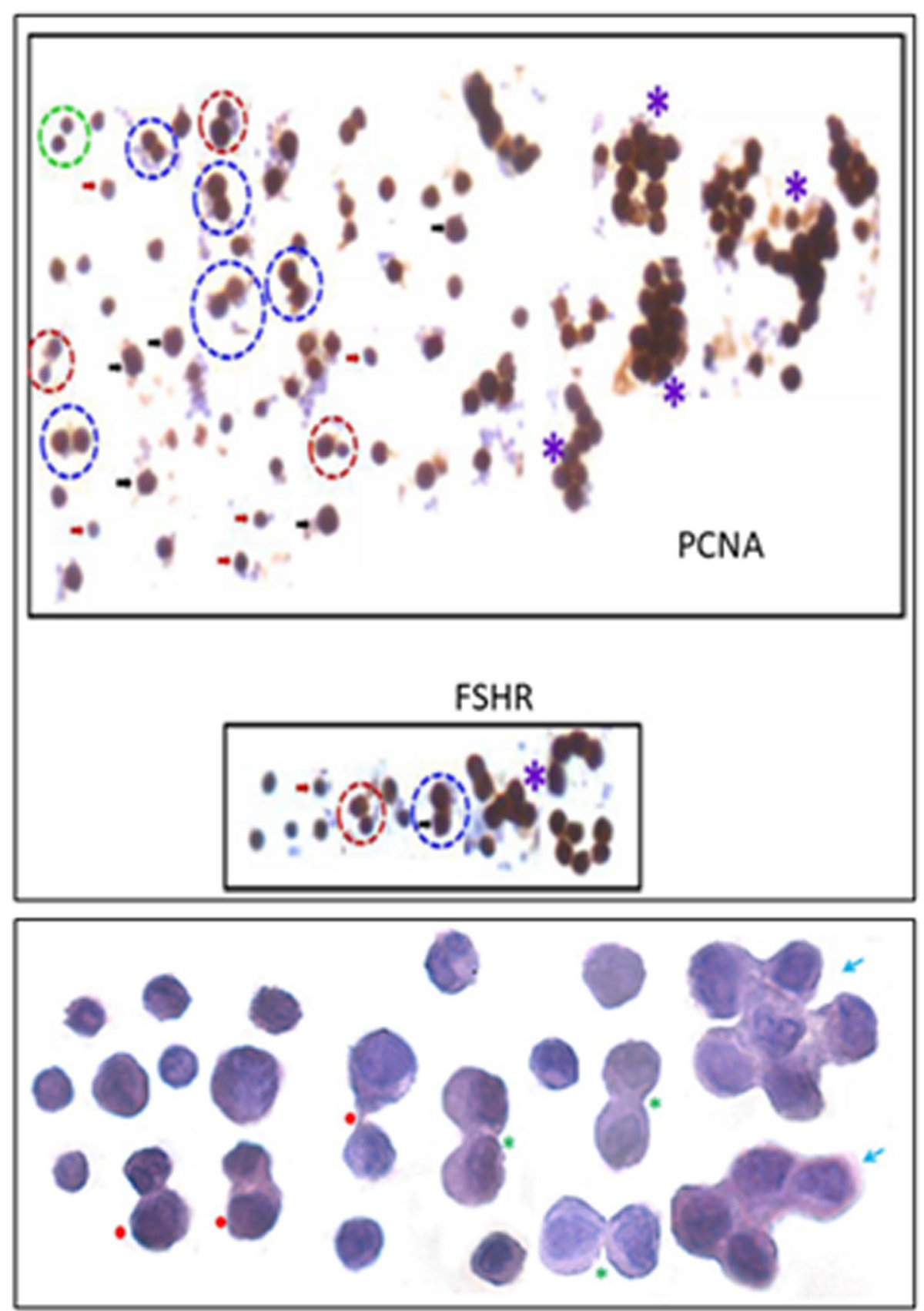

Fig. 22 Two populations of stem cells including VSELs (red arrow) and slightly bigger EnSCs (black arrow). Stem cells smears from the uterus showed asymmetrical (red broken circle), symmetrical (blue broken circle) divisions and clonal expansion (purple asterix). These stem cells expressed PCNA and FSHR. Higher magnification clearly showed asymmetrical (red asterix), symmetrical (green asterix) divisions and clonal expansion (blue arrow) [57,68] Scale: $20 \mu \mathrm{m}$

stem cells including VSELs isolated from human umbilical cord blood and peripheral blood. Sex hormones in vitro enhanced clonogenic growth of the hematopoietic stem cells. Zbucka-Kretowska et al.
[74] reported statistically significant mobilization of VSELs and HSCs (and not endothelial progenitors) into the peripheral blood of 15 female patients undergoing FSH therapy in the infertility clinics. This body 

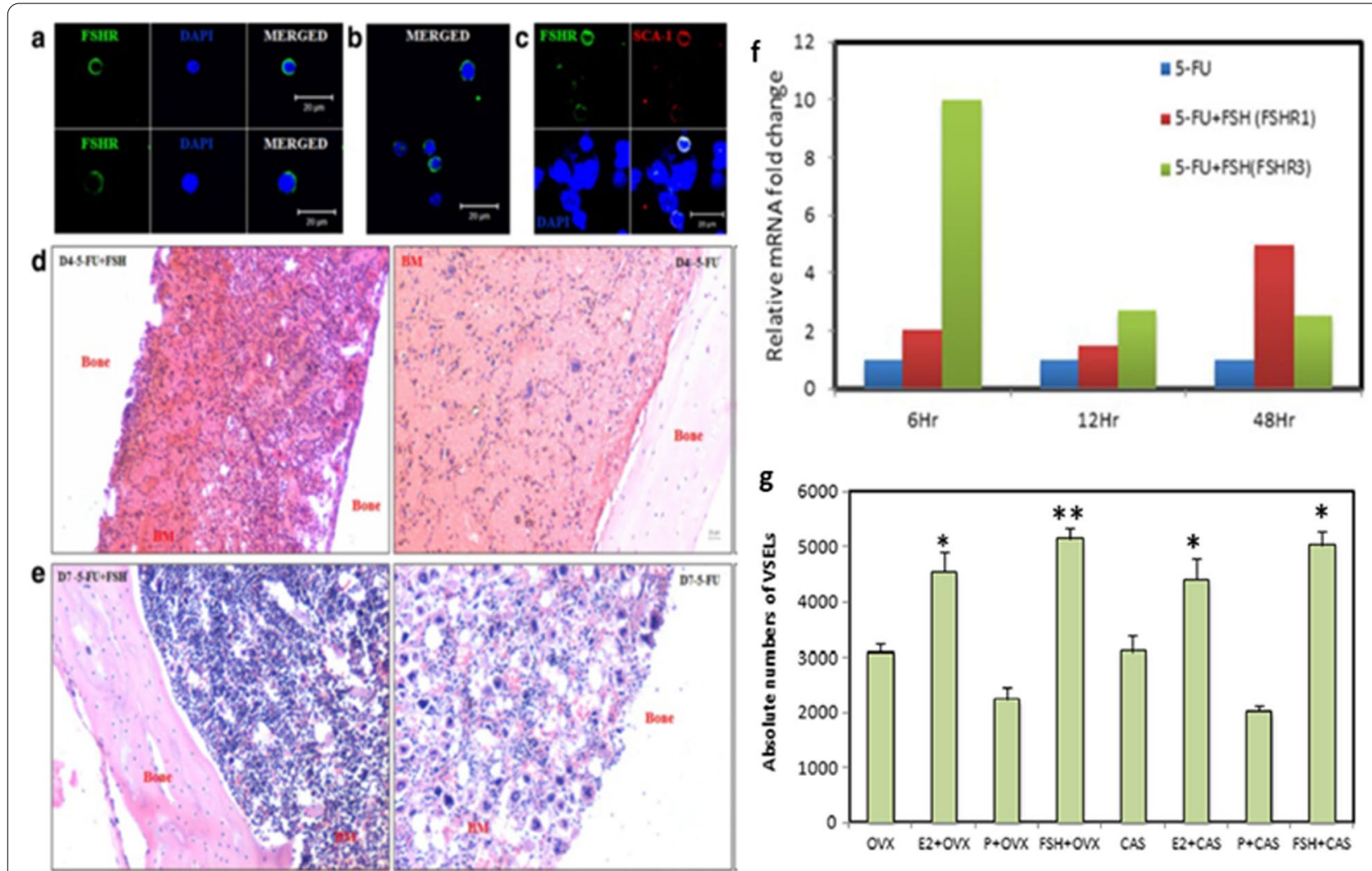

Fig. 23 (a-b) Mouse bone marrow VSELs and HSCs also express FSHR. (c) Also note co-expression of a stem cell marker SCA-1 and FSHR. (d-e) Mouse decalcified bone sections after chemoablation (5-flurouracil, $150 \mathrm{mg} / \mathrm{kg}$ ) to study the effect of FSH on resumption of hematopoiesis. Left panel in $\mathrm{d} \&$ e are FSH treatment to chemoablated mice on D4 and D7 compared to no treatment in the right panel. FSH enhanced hematopoiesis by almost $72 \mathrm{~h}$ by exerting a direct action on VSELs [72]. $(\mathrm{f})$ As evident in 5-FU treated mouse bone marrow, 10 -fold increase in FSHR3 was observed $6 \mathrm{~h}$ after FSH (5 IU) treatment [56]. (g) Ovariectomized and castrated mice were treated with Estradiol (E2, 2 $\mu \mathrm{g} / \mathrm{day})$, progesterone ( $\mathrm{P}, 1 \mathrm{mg} / \mathrm{Kg} / \mathrm{day})$ and FSH (5IU per day) for 7 days and absolute numbers of VSELS were enumerated. FSH exerted a direct action and VSELs numbers were increased similar to after E2 treatment whereas P did not exert any effect [77]. Scale: $20 \mu \mathrm{m}$

of literature suggests developmental origin of VSELs and HSCs from germ lineage. Receptors for pituitary and ovarian hormones are also reported on leukemic cell lines and blasts. Virant-Klun [75] discussed the developmental link between germ lineage and hematopoiesis in humans and later on a review was published discussing why the hematopoietic stem cells are so 'sexy' [76].

Functional studies were reported in vivo by our group on adult mice bone marrow showing a direct effect of FSH on hematopoiesis [72]. Treatment with 5 fluorouracil $(5-\mathrm{FU}, 150 \mathrm{mg} / \mathrm{Kg}$ ) depletes the bone marrow of mature blood cells. These chemoablated mice were studied with and without FSH (5IU) treatment on days 2, 4 and 10 after chemotherapy. FSH treatment enhanced hematopoietic recovery by at least $72 \mathrm{~h}$ in
5-FU-treated mice and this action of FSH was mediated via Fshr3 and almost 10-fold increase in Fshr-3 was observed by $6 \mathrm{~h}$ of FSH treatment [72]. In another study, Ganguly et al. [77] treated ovariectomized and castrated mice with E, P \& FSH and as evident FSH was observed to exert profound effects and resulted in increased numbers of VSELs by flow cytometry studies (Fig. 23).

Effect of FSH treatment was also studied on stem cells in bone marrow cell smears. For this 5-FU treated mice were further treated with FSH (5IU) on days $4 \& 5$ and sacrificed on Day 6 . Bone marrow was flushed out and used to make cell smears (Fig. 24). One could easily visualize asymmetrical, symmetrical divisions and clonal expansion in the stem cells compartment [56]. 


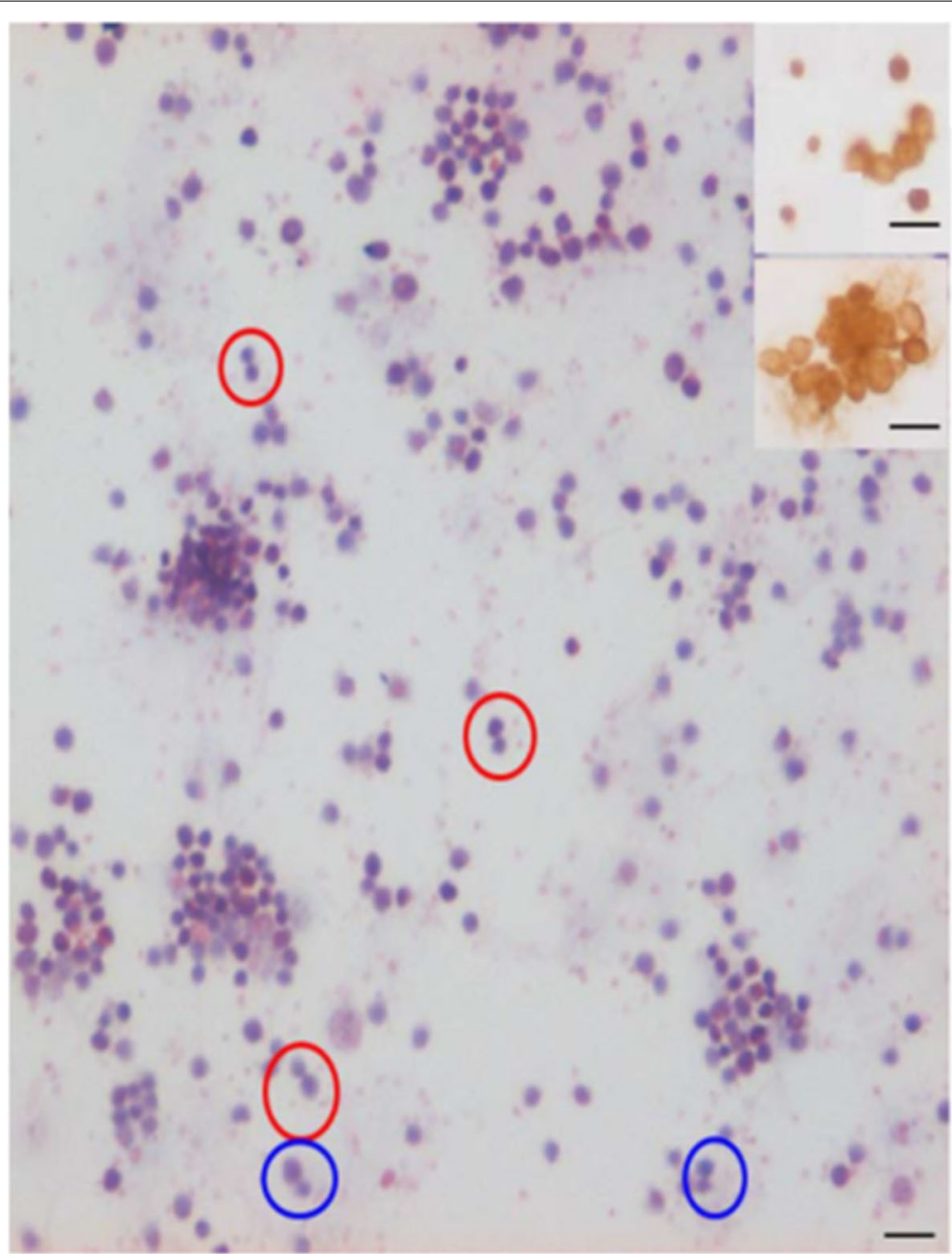

Fig. 24 A. H\&E stained bone marrow stem cell smears prepared from a chemoablated mice $(5-\mathrm{FU}, 150 \mathrm{mg} / \mathrm{Kg})$ after treatment on Days 4 \& 5 with FSH (5IU) and sacrificed on Day 6. One could see various types of cell divisions including ACD (blue circle), SCD (red circle) and clonal expansion. Insert shows that the cells enriched by 5-FU in the bone marrow express OCT-4 [57]. Scale: $20 \mu \mathrm{m}$

Similarly, VSELs in mouse prostate are regulated by FSH and only Fshr3 is expressed in adult prostate and not the canonical Fshr1 (unpublished data by our group). These results are in contradiction with recent scRNAseq study [78] which negated presence of stem cells in mice and human prostate. We had pointed out reasons for their inability to detect stem cells $[79,80]$.

In view of the research findings compiled in this review, it becomes imperative to appreciate a wider landscape for FSH action which is so far limited to Sertoli cells in testes and Granulosa cells in ovaries.

\section{Acknowledgments}

We acknowledge contributions of all who have reported on various aspects of FSH-FSHR biology. Pardon us for our ignorance if we have not quoted some work which may be directly relevant.

\section{Authors' contributions}

Manuscript was prepared by DB based on work published over a decade in her lab. All the authors read and approved the final version.

\section{Funding}

Financial support was provided by Indian Council of Medical Research, Government of India, New Delhi, India.

\section{Availability of data and materials}

It should be present and appropriate for data policy associated with the journal (stated in the submission guidelines). Not applicable.

\section{Declarations}

Ethics approval and consent to participate

Not applicable. This review does not include any clinical data. All research done on mice and other animal models is already published and approved by Institute Animal Ethics Committee of NIRRH. Experiments carried out in the present study were approved by NIRRH Institutional Animal Ethics Committee (78/GO/ReBi/SL/99/CPCSEA dated-11/03/1999). 


\section{Consent for publication}

NIRRH No. REV/1082/06-2021.

\section{Competing interests}

The authors have no conflict of interest to disclose.

\section{Author details}

${ }^{1}$ Stem Cell Biology Department, ICMR- National Institute for Research in Reproductive Health, Jehangir Merwanji Street, Parel, Mumbai 400012 , India. ${ }^{2}$ Present address: Department of Ophthalmology and Visual Sciences, University of Nebraska Medical Center, Omaha, NE, USA.

Received: 20 June 2021 Accepted: 16 September 2021

Published online: 30 October 2021

\section{References}

1. Coss D. Commentary on the recent FSH collection: Known knowns and known unknowns. Endocrinology. 2020;161:bqz035.

2. Simoni M, Brigante G, Rochira V, Santi D, Casarini L. Prospects for FSH treatment of male infertility. J Clin Endocrinol Metab. 2020;105(7). https:// doi.org/10.1210/clinem/dgaa243.

3. Simoni M, Santi D. FSH treatment of male idiopathic infertility: time for a paradigm change. Andrology. 2020;8:535-44.

4. Simoni M, Huhtaniemi I, Casarini L, Santi D, editors. Follicle-stimulating hormone: fertility and beyond. Lausanne: Frontiers Media; 2019. https:// doi.org/10.3389/978-2-88963-204-6.

5. Bhartiya D, Patel H. An overview of FSH-FSHR biology and explaining the existing conundrums. J Ovarian Research 2021 (submitted)

6. Bhartiya D, Singh P, Kaushik A, Sharma D. The role of very small embryonic-like stem cells (VSELs) in reproductive tissues. In springer nature book entitled stem cells in reproductive tissues and organs-from fertility to Cancer. Editor Irma Virant Klun.

7. Ratajczak MZ, Ratajczak J, Kucia M. Very small embryonic-like stem cells (VSELs): an update and future directions. Circ Res. 2019;124:208-10.

8. Bhartiya D, Shaikh A, Anand S, Patel H, Kapoor S, Sriraman K, et al. Endogenous, very small embryonic-like stem cells: critical review, therapeutic potential and a look ahead. Hum Reprod Update. 2016;23:41-76.

9. Chrusciel M, Ponikwicka-Tyszko D, Wolczynski S, Huhtaniemi I, Rahman NA. Extragonadal FSHR expression and function-is it real? Front Endocrinol. 2019;4(10):32.

10. Lizneva D, Rahimova A, Kim SM, Atabiekov I, Javaid S, et al. FSH beyond fertility. Front Endocrinol (Lausanne). 2019;10:136. https://doi.org/10. 3389/fendo.2019.00136.

11. Kumar TR. Extragonadal FSH receptor: is it real? Biol Reprod. 2014;91(4):99. https://doi.org/10.1095/biolreprod.114.124222.

12. Sellers ZP, Bujko K, Schneider G, Kucia M, Ratajczak MZ. Novel evidence that pituitary sex hormones regulate migration, adhesion, and proliferation of embryonic stem cells and teratocarcinoma cells. Oncol Rep. 2018;39:851-9.

13. Li L, Dong J, Yan L, Yong J, Liu X, et al. SingleCell RNASeq analysis maps development of human germline cells and gonadal niche interactions. Cell Stem Cell. 2017;20(6):858-73.

14. Cheung J, Lokman NA, Abraham RD, Macpherson AM, Lee E, et al. Reduced gonadotrophin receptor expression is associated with a more aggressive ovarian cancer phenotype. Int J Mol Sci. 2020;22(1):71. https:// doi.org/10.3390/ijms22010071.

15. Bose CK. Follicle stimulating hormone receptor in ovarian surface epithelium and epithelial ovarian cancer. Oncol Res. 2008;17:231-8.

16. Parrott JA, Doraiswamy V, Kim G, Mosher R, Skinner MK. Expression and actions of both the follicle stimulating hormone receptor and the luteinizing hormone receptor in normal ovarian surface epithelium and ovarian cancer. Mol Cell Endocrinol. 2001;172:213-22.

17. Chen X, Aravindakshan J, Yang Y, Sairam MR. Early alterations in OSE and induction of ovarian epithelial tumors triggered by loss of FSHR. Neoplasia. 2007;9:521-31.

18. Zhang XY, Chen J, Zheng YF, Gao XL, Kang Y, Liu JC, et al. Follicle-stimulating hormone peptide can facilitate paclitaxel nanoparticles to target ovarian carcinoma in vivo. Cancer Res. 2009:69:6506-14.
19. Li Y, Ganta S, Cheng C, Craig R, Ganta RR, Freeman LC. FSH stimulates ovarian cancer cell growth by action on growth factor variant receptor. Mol Cell Endocrinol. 2007;267:26-37.

20. Bhartiya D, Sriraman K, Gunjal P, Modak H. Gonadotropin treatment augments postnatal oogenesis and primordial follicle assembly in adult mouse ovaries? J Ovarian Res. 2012;5:32.

21. Bhartiya D, Singh J. FSH-FSHR3-stem cells in ovary surface epithelium: basis for adult ovarian biology, failure, aging, and cancer. Reproduction. 2015;149:R35-48.

22. Johnson J, Canning J, Kaneko T. Pru JK, Tilly JL. Germline stem cells and follicular renewal in the postnatal mammalian ovary. Nature 2004:428:145-150.

23. Parte S, Bhartiya D, Telang J, Daithankar V, Salvi V, Zaveri K, et al. Detection, characterization, and spontaneous differentiation in vitro of very small embryonic-like putative stem cells in adult mammalian ovary. Stem Cells Dev. 2011;20:1451-64.

24. Patel H, Bhartiya D, Parte S, Gunjal P, Yedurkar S, Bhatt M. Follicle stimulating hormone modulates ovarian stem cells through alternately spliced receptor variant FSH-R3. J Ovarian Res. 2013;6:52.

25. Patel H, Bhartiya D, Parte S. Further characterization of adult sheep ovarian stem cells and their involvement in neo-oogenesis and follicle assembly. J Ovarian Res. 2018;11(1):3. https://doi.org/10.1186/ s13048-017-0377-5.

26. Bhartiya D, Sharma D. Ovary does harbor stem cells - size of the cells matter! J Ovarian Res. 2020;13(1):39. https://doi.org/10.1186/ s13048-020-00647-2.

27. Sriraman K, Bhartiya D, Anand S, Bhutda S. Mouse ovarian very small embryonic-like stem cells resist chemotherapy and retain ability to initiate oocyte-specific differentiation. Reprod Sci. 2015;22:884-903.

28. Bhartiya D, Patel H. Ovarian stem cells-resolving controversies. J Assist Reprod Genet. 2018:35:393-8.

29. Virant-Klun I, Zech N, Rozman P, Vogler A, Cvjeticanin B, Klemenc P, et al. Putative stem cells with an embryonic character isolated from the ovarian surface epithelium of women with no naturally present follicles and oocytes. Differentiation. 2008;76:843-56.

30. Wang JJ, Ge W, Liu JC, Klinger FG, Dyce PW, De Felici M, et al. Complete in vitro oogenesis: retrospects and prospects. Cell Death Differ. 2017:24(11):1845-52.

31. Woods DC, White YA, Tilly JL. Purification of oogonial stem cells from adult mouse and human ovaries: an assessment of the literature and a view toward the future. Reprod Sci. 2013;20(1):7-15.

32. Zou $K$, Yuan Z, Yang Z, Luo $H$, Sun $K$, et al. Production of offspring from a germline stem cell line derived from neonatal ovaries. Nat Cell Biol. 2009;11(5):631-6.

33. Kenda Suster N, Virant-Klun I. Presence and role of stem cells in ovarian cancer. World J Stem Cells. 2019;11(7):383-97. https://doi.org/10.4252/ wjsc.v11.i7.383.

34. Virant-Klun I, Kenda-Suster N, Smrkolj S. Small putative NANOG, SOX2, and SSEA-4-positive stem cells resembling very small embryonic-like stem cells in sections of ovarian tissue in patients with ovarian cancer. J Ovarian Res. 2016:9:12

35. Virant-Klun I, Stimpfel M. Novel population of small tumour-initiating stem cells in the ovaries of women with borderline ovarian cancer. Sci Rep. 2016;6:34730.

36. Loret N, Denys H, Tummers P, Berx G. The role of epithelial-to-mesenchymal plasticity in ovarian cancer progression and therapy resistance. Cancers (Basel). 2019 Jun 17;11(6):838. https://doi.org/10.3390/cancers11060838.

37. Parte S, Bhartiya D, Manjramkar DD, et al. Stimulation of ovarian stem cells by follicle stimulating hormone and basic fibroblast growth factor during cortical tissue culture. J Ovarian Res. 2013;6:20.

38. Sullivan RR, Faris BR, Eborn D, Grieger DM, Cino-Ozuna AG, Rozell TG. Follicular expression of follicle stimulating hormone receptor variants in the ewe. Reprod Biol Endocrinol. 2013;11:113.

39. Gerasimova T, Thanasoula MN, Zattas D, Seli E, Sakkas D, Lalioti MD. Identification and in vitro characterization of follicle stimulating hormone (FSH) receptor variants associated with abnormal ovarian response to FSH. J Clin Endocrinol Metab. 2010;95:529-36.

40. Zhou J, Huang Y, Li L, Zhu L, Zhang D, Zhang S, et al. Identification of two novel, alternatively spliced mRNA transcripts of the human follicle-stimulating hormone receptor. Mol Reprod Dev. 2013 Nov;80(11):916-23. 
41. Perales-Puchalt A, Svoronos N, Rutkowski MR, Allegrezza MJ, Tesone AJ, Payne KK, et al. Follicle-stimulating hormone receptor is expressed by most ovarian cancer subtypes and is a safe and effective immunotherapeutic target. Clin Cancer Res. 2017;23:441-53.

42. Mamas E, Mavrogianni D, Raouasnte R, Karkatzoulis S, Liokari E, Drakakis $P$, et al. Pilot study: alternative spliced variants of the follicle-stimulating hormone receptor gene in greek women undergoing in vitro fertilization (IVF). HJOG. 2019;18:155-62.

43. Karakaya C, Guzeloglu-Kayisli O, Hobbs RJ, Gerasimova T, Uyar A, Erdem $\mathrm{M}$, et al. Follicle-stimulating hormone receptor (FSHR) alternative skipping of exon 2 or 3 affects ovarian response to FSH. Mol Hum Reprod. 2014;20:630-43.

44. Song K, Dai L, Long X, Wang W, Di W. Follicle-stimulating hormone promotes the proliferation of epithelial ovarian cancer cells by activating sphingosine kinase. Sci Rep. 2020;10(1):13834. https://doi.org/10.1038/ s41598-020-70896-0.

45. Sharma D, Bhartiya D. Stem cells in adult mice ovaries form germ cell nests and undergo meiosis and neo-oogenesis on regular basis during estrus cycle. Human Reproduction. 2021 under review.

46. Yarney TA, Fahmy MH, Sairam MR, Khan H, Macdonald EA. Ontogeny of FSH receptor messenger ribonucleic acid transcripts in relation to FSH secretion and testicular function in sheep. JMol Endocrinol. 1997;18:113-25.

47. Kelton CA, Cheng SVY, Nugent NP, Schweickhardt RL, Rosenthal JL, Overton $\mathrm{SA}$, et al. The cloning of the human follicle stimulating hormone receptor and its expression in COS-7, CHO, and Y-1 cells. Mol Cell Endocrinol. 1992;89:141-51.

48. Ferlin A, Pengo M, Selice R, Salmaso L, Garolla A, Foresta C. Analysis of single nucleotide polymorphisms of FSH receptor gene suggests association with testicular cancer susceptibility. Endocr Relat Cancer. 2008;15:429-37.

49. Radu A, Pichon C, Camparo P, Antoine M, Allory Y, Couvelard A, et al. Expression of follicle-stimulating hormone receptor in tumor blood vessels. N Engl J Med. 2010;363:1621-30.

50. Bhartiya D, Kasiviswanathan S, Unni SK, Pethe P, Dhabalia JV, Patwardhan $S$, et al. Newer insights into premeiotic development of germ cells in adult human testis using Oct-4 as a stem cell marker. J Histochem Cytochem. 2010;58(12):1093-106. https://doi.org/10.1369/jhc.2010.956870.

51. Anand S, Bhartiya D, Sriraman K, Mallick A. Underlying mechanisms that restore spermatogenesis on transplanting healthy niche cells in busulphan treated mouse testis. Stem Cell Rev. 2016;12:682-97.

52. Patel H, Bhartiya D. Testicular stem cells express follicle-stimulating hormone receptors and are directly modulated by FSH. Reprod Sci. 2016;11:1493-508.

53. Kurkure P, Prasad M, Dhamankar V, Bakshi G. Very small embryonic-like stem cells (VSELS) detected in azoospermic testicular biopsies of adult survivors of childhood cancer. Reprod Biol Endocrinol. 2015;13:122.

54. Stimpfel M, Skutella T, Kubista M, Malicev E, Conrad S, Virant-Klun I. Potential stemness of frozen-thawed testicular biopsies without sperm in infertile men included into the in vitro fertilization programme. J Biomed Biotechnol. 2012;2012:291038.

55. Kaushik A, Bhartiya D. Additional evidence to establish existence of two stem cell populations including vsels and sscs in adult mouse testes. Stem Cell Rev Rep. 2020;16:992-1004.

56. Kaushik A, Anand S, Bhartiya D. Altered biology of testicular VSELs and SSCs by neonatal endocrine disruption results in defective spermatogenesis, reduced fertility and tumor initiation in adult mice. Stem Cell Rev Rep. 2020;16:893-908.

57. Bhartiya D, Patel H, Ganguly R, Shaikh A, Shukla Y, Sharma D, et al. Novel insights into adult and cancer stem cell biology. Stem Cells Dev. 2018;27(22):1527-39.

58. Jones TD, Ulbright TM, Eble JN, Baldridge LA, Cheng L. OCT4 staining in testicular tumors: a sensitive and specific marker for seminoma and embryonal carcinoma. Am J Surg Pathol. 2004;28:935-40.

59. Marca AL, Giulini S, Orvieto R, Leo VD, Volpe A. Anti-müllerian hormone concentrations in maternal serum during pregnancy. Hum Reprod. 2005;20:1569-72.

60. Sacchi S, Sena P, Esposti CD, Lui J, La Marca A. Evidence for expression and functionality of $\mathrm{FSH}$ and $\mathrm{LH} / \mathrm{hCG}$ receptors in human endometrium. J Assist Reprod Genet. 2018 Sep;35(9):1703-12.

61. Stilley JAW, Christensen DE, Dahlem KB, Guan R, Santillan DA, et al. FSH receptor (FSHR) expression in human extragonadal reproductive tissues and the developing placenta, and the impact of its deletion on pregnancy in mice. Biol Reprod. 2014;91:74.
62. Robin B, Planeix F, Garau XS, Pichon C, Olesen TK, et al. Follicle-stimulating hormone receptor expression in endometriotic lesions and the associated vasculature: an immunohistochemical study. Reprod Sci. 2016;23:885-91.

63. Ponikwicka-Tyszko D, Chrusciel M, Stelmaszewska J, Bernaczyk P, Maria $\mathrm{S}$, et al. Functional expression of FSH receptor in endometriotic lesions. J Clin Endocrinol Metab. 2016;101:2905-14.

64. Plewka D, Marczyński J, Morek M, Bogunia E, Plewka A. Receptors of hypothalamic-pituitary-ovarian-axis hormone in uterine myomas. Biomed Res Int. 2014;2014:521313.

65. Singh P, Bhartiya D. Pluripotent stem (VSELs) and progenitor (EnSCs) cells exist in adult mouse uterus and show cyclic changes across estrus cycle. Reprod Sci. 2021;28:278-90.

66. Gunjal P, Bhartiya D, Metkari S, Manjramkar D, Patel H. Very small embryonic-like stem cells are the elusive mouse endometrial stem cells--a pilot study. J Ovarian Res. 2015;8:9.

67. Bhartiya D, James K. Very small embryonic-like stem cells (VSELs) in adult mouse uterine perimetrium and myometrium. J Ovarian Res. 2017;10:29.

68. James K, Bhartiya D, Ganguly R, Kaushik A, Gala K, Singh P, et al. Gonadotropin and steroid hormones regulate pluripotent very small embryoniclike stem cells in adult mouse uterine endometrium. J Ovarian Res. 2018;11:83.

69. Singh P, Metkari SM, Bhartiya D. Altered uterine stem cells by endocrine disruption initiate uteropathies in adult mice. Submitted to Reproduction. 2021.

70. Shaikh A, Nagvenkar P, Pethe P, Hinduja I, Bhartiya D. Molecular and phenotypic characterization of CD133 and SSEA4 enriched very small embryonic-like stem cells in human cord blood. Leukemia. 2015;9:1909-17.

71. Mierzejewska K, Borkowska S, Suszynska E, Suszynska M, PoniewierskaBaran A, et al. Hematopoietic stem/progenitor cells express several functional sex hormone receptors-novel evidence for a potential developmental link between hematopoiesis and primordial germ cells. Stem Cells Dev. 2015;24(8):927-37.

72. Shaikh A, Bhartiya D, Kapoor S, Nimkar H. Delineating the effects of 5-fluorouracil and follicle-stimulating hormone on mouse bone marrow stem/progenitor cells. Stem Cell Res Ther. 2016;7(1):59. https://doi.org/10. 1186/s13287-016-0311-6.

73. Abdelbaset-Ismail A, Suszynska M, Borkowska S, Adamiak M, Ratajczak J, et al. Human haematopoietic stem/progenitor cells express several functional sex hormone receptors. J Cell Mol Med. 2016;20(1):134-46. https:// doi.org/10.1111/jcmm.12712.

74. Zbucka-Kretowska M, Eljaszewicz A, Lipinska D, Grubczak K, Rusak M, et al, Effective mobilization of very small embryonic-like stem cells and hematopoietic stem/progenitor cells but not endothelial progenitor cells by follicle-stimulating hormone therapy. Stem Cells Int. 2016;2016:8530207. https://doi.org/10.1155/2016/8530207.

75. Virant-Klun I. Very small embryonic-like stem cells: a potential developmental link between germinal lineage and hematopoiesis in humans. Stem Cells Dev. 2016;25(2):101-13. https://doi.org/10.1089/scd.2015. 0275 .

76. Ratajczak MZ. Why are hematopoietic stem cells so 'sexy'? On a search for developmental explanation. Leukemia. 2017;31(8):1671-7. https://doi. org/10.1038/leu.2017.148

77. Ganguly R, Metkari S, Bhartiya D. Dynamics of bone marrow VSELs and HSCs in response to treatment with gonadotropin and steroid hormones, during pregnancy and evidence to support their asymmetric/symmetric cell divisions. Stem Cell Rev Rep. 2018;14(1):110-24. https://doi.org/10. 1007/s12015-017-9781-x.

78. Karthaus WR, Hofree M, Choi D, Linton EL, Turkekul M, et al. Regenerative potential of prostate luminal cells revealed by single-cell analysis. Science. 2020;368(6490):497-505.

79. Bhartiya D, Kaushik A, Singh P, Sharma D. Will single-cell RNAseq decipher stem cells biology in normal and cancerous tissues? Hum Reprod Update. 2021;27(2):421. https://doi.org/10.1093/humupd/dmaa058.

80. Bhartiya D. Adult tissue-resident stem cells-fact or fiction? Stem Cell Res Ther. 2021;12(1):73. https://doi.org/10.1186/s13287-021-02142-x.

\section{Publisher's Note}

Springer Nature remains neutral with regard to jurisdictional claims in published maps and institutional affiliations. 